\title{
Molecular and Sub-Cellular Gametogenic Machinery of Stem and Germline Cells Across Metazoa
}

\author{
Andrey I. Shukalyuk ${ }^{1}$ and Valeria V. Isaeva ${ }^{2}$ \\ Institute of Biomaterials and Biomedical Engineering, \\ University of Toronto, Toronto, Ontario, \\ ${ }^{2} A$. V. Zhirmunsky Institute of Marine Biology of The Far Eastern Branch of \\ The Russian Academy of Sciences, Vladivostok and A. N. Severtsov Institute of \\ Ecology and Evolution of The Russian Academy of Science, Moscow, \\ ${ }^{1}$ Canada \\ ${ }^{2}$ Russia
}

\section{Introduction}

Metazoan life cycle and development include two main types of stem cells: the germline cells and the somatic stem cell lineages (Hogan, 2001; Rinkevich, 2009; Srouji \& Extavour, 2011). In animals with asexual reproduction, the germ lineage is not segregated during embryogenesis, and the line of pluripotent stem cells is maintained continuously throughout the life of an individual or a colony, being predecessors of germ cells and a wide spectrum of somatic cells (Buss, 1987; Isaeva, 2011; Rinkevich, 2009; Sköld et al., 2009). Examples of such pluripotent gametogenic stem cells include sponge archaeocytes, cnidarian interstitial cells, planarian neoblasts, ascidian hemoblasts and stem cells of colonial rhizocephalans (reviews: Isaeva et al., 2008, 2009; Rinkevich et al., 2009; Sköld et al., 2009; Srouji \& Extavour, 2011). In addition to the germline segregation by preformation, or mosaic developmental mode and epigenesis, or regulative mode (Extavour, 2008; Extavour \& Akam, 2003; Gustafson \& Wessel, 2010), somatic embryogenesis was also recognized (Buss, 1987; Blackstone \& Jasker, 2003; Gustafson \& Wessel, 2010; Rinckevich et al., 2009; Rosner et al., 2009). Earlier, somatic embryogenesis as natural cloning in animals was termed blastogenesis (Berrill, 1961; Ivanova-Kazas, 1996). In the life cycle of colonial animals, one generation of oozooid (an individual that has developed from an egg) alternates with numerous generations of blastozooids, with alternating morphogenetic processes: embryogenesis and blastogenesis (Ivanova-Kazas, 1996). Many animals, including placozoans, sponges, cnidarians, platyhelminths, nemerteans, entoproctans, ectoproctans, annelids, hemichordates and urochordates are capable of somatic embryogenesis (Buss 1987; Blackstone \& Jasker, 2003; Gustafson \& Wessel, 2010; Rosner et al., 2009). Among arthropods, many parasitic rhizocephalan crustaceans (Rhizocephala: Cirripedia: Crustacea) have asexual reproduction, somatic embryogenesis by budding without separation of blastozooids resulting in the emergence of colonial organization 
(Høeg \& Lützen, 1993, 1995; Høeg et al., 2005). We have found undifferentiated stem cells in stolons, buds and ovary rudiments of the colonial rhizocephalans Polyascus polygenea (Isaeva et al., 2001, 2004; Shukalyuk, 2002; Shukalyuk et al., 2005, 2007) and Peltogasterella gracilis (Isaeva et al., 2003; Shukalyuk et al., 2001, 2005). The rhizocephalan stem cells take part in the morphogenesis of the earliest buds, and later migrate to the developing ovary as primary germ cells. So, pluripotent gametogenic stem cells are a cellular source in the realization of reproductive strategy including both sexual and asexual reproduction in colonial rhizocephalan.

All stem cells are characterized by two common properties that extend across diverse taxa: first, the capacity for self-renewal, the ability to propagate without loss of stemness property; second, the ability to give rise to numerous progeny that are fated for further differentiation into specialized cells (Alié et al., 2011; Cox et al., 1998; Srouji \& Extavour, 2011; Watanabe et al. 2009). Depending on the breadth of the potential range of cell differentiation, totipotent, pluripotent, multipotent, oligopotent, and unipotent stem cells are distinguished, but this terminology is not unified (see Isaeva, 2010; 2011).

Female germline cells can be qualified as unipotent, since they produce only one type of differentiated cells, and totipotent, taking into account their potential of developing into a whole organism. There is no doubt that differentiated and deeply specialized gametes are unipotent cells producing only oocytes or sperm under specific signaling control of their niche. However, the progenitors of germline cells are multipotent or even pluripotent, also capable of differentiating into somatic lineages in vitro or in vivo, causing various germlinebased embryonic tumorogenesis.

Stem cells of invertebrates with asexual reproduction are capable of differentiation into both germline and all, most or many somatic cell types are traditionally referred to as totipotent, pluripotent or multipotent. We consider here these cells as gametogenic pluripotent stem cells. In asexually reproducing invertebrates no early segregation of the germ cell lineage is observed. The lineage of pluripotent, traditionally referred to as totipotent, stem cells ensures both sexual and asexual reproduction over the entire life span of an individual or a colony. These pluripotent stem cells can differentiate into gametes and somatic cells in adult organisms. We studied pluripotent gametogenic stem cells in asexually reproducing representatives of five animal types: archaeocytes in the sponge (Porifera) Oscarella malakhovi (Isaeva \& Akhmadieva, 2011), interstitial cells in the colonial hydroids (Cnidaria) Obelia longissima and Ectopleura crocea (Isaeva et al., 2011), neoblasts in the planarian (Platyhelmintes) Girardia tigrina (Isaeva et al., 2005), stem cells in the colonial rhizocephalans (Arthropoda) Peltogasterella gracilis and Polyascus polygenea (Isaeva et al., 2003, 2004; Shukalyuk et al., 2005, 2007), hemoblasts, stem cells in the colonial ascidian (Chordata) Botryllus tuberatus (Akhmadieva et al., 2007), and also embryonic stem cells as a benchmark for pluripotency, using in vitro culture, electron microscopic, histological, histochemical and molecular methods.

Mammalian embryonic stem cells (ESCs) are considered as a standard cell culture model for studying pluripotency (Do \& Schöler, 2009). In our studies, as well as in the present review, we compare our data on invertebrate pluripotent stem cells with the information on the molecular signature of pluripotent stem cells of various animals, including mouse ESCs (Isaeva et al., 2003; Shukalyuk, 2009; Shukalyuk et al., 2005, 2011; Shukalyuk \& Stanford, 
2008), taking into consideration that mammalian ESCs in vitro are in some sense artifacts of tissue culture (Shostak, 2006; Zwaka \& Thomson, 2005).

In this review, we reveal some common principles in the sub-cellular and molecular machinery maintaining pluripotency and gametogenic potentiality. We hypothesize that evolutionary conserved molecular mechanisms underlie pluripotency, including gametogenic potentiality in germline, embryonic stem cells and other pluripotent stem cells of different metazoans.

\section{The molecular and sub-cellular machinery of stem cell specifications}

In all multicellular organisms, a stem cell system serves as a crucial cellular source during embryonic development building de novo the entire organism and during adulthood regenerating all types of cells and tissues of the individual. In colonial organisms with asexual reproduction in their life cycle, stem cells can be toti/pluripotent, producing not only all somatic types but germline as well. One of the critical features of the stem cell is self-renewal. Stem cells can divide indefinitely without losing their potent capacity and ability to differentiate. Typical stem cell morphology is characterized by a relatively organelle-free cytoplasm, large rounded nucleus and large prominent nucleolus (nucleoli) and diffuse euchromatin, presumably capable of genome-wide active transcription. They have also a significant proportion of inactive heterochromatin, which is silenced by histone methylation or siRNAs and appear as a compact electron-dense material at the ultrastructural level. Also, based on the chromatin organization state, stem cells commonly have the nuclear-tocytoplasmic ratio shifted toward the nucleus of the cell. These morphological characteristics of stem cells are applicable for the germline cells as well. However, when germcells are specified they will stop actively proliferating until they reach the rudiment of the gonads. It is belived that germline cells will keep their toti-/pluripotent properties and self-renewal capacity while continuing to migrate and differentiate to gametes. Remarkable properties of germline cells, underlining their morpho-functional similarities and differences with other toti-/pluripotent cells, are our main focus in this section.

\subsection{Germline cells}

Germline cells across Metazoa are specialized cells which are usually specified in very early embryonic development, preserving their capacity to carry out important information about the entire organism, passing it down to the next generation. During preformation, maternally inherited factors of the egg cell, localized in specific areas of the cleaving zygote, leave a specific imprint in the blastomeres, which specialize into germline progenitors. It is believed that epigenesis gives an advantage for the multicellular organism in adaptation and species survival because it does not rely on the quality of a few blastomeres. Instead, during epiginesis, early blastomeres have equal developmental potential and have similar capacity contributing to the developing organism and germline specification (Fig. 1).

Germline cells can be indentified by their specific morpho-genetic signature. According to Extavour (Extavour, 2008; Extavour \& Akam 2003), undifferentiated germ cells can be distinguished from somatic cells by several criteria, in addition to typical stem cell characteristics described above. The morphological features are mainly "default" characteristics of the undifferentiated state (Alié et al., 2011). An exception is the key 
organelles of germline cells referred to as germ (germinal) granules or nuage. They are considered to be a germline hallmark across the animal kingdom (Brown\& Swalla, 2007; Eddy et al., 1975; Ikenishi, 1998; Lim \& Kai, 2007; Mahowald, 2001; Matova \& Cooley, 2001). Evolutionary conserved germ-cell-specific gene expression marks germline cells distinguishing them from somatic cells in all studied metazoans (Ewen-Camden et al., 2010; Extavour, 2008; Leatherman, Jongens, 2003; Matova \& Cooley, 2001; Seydoux \& Braun, 2006; Sroji \& Extavour, 2011).

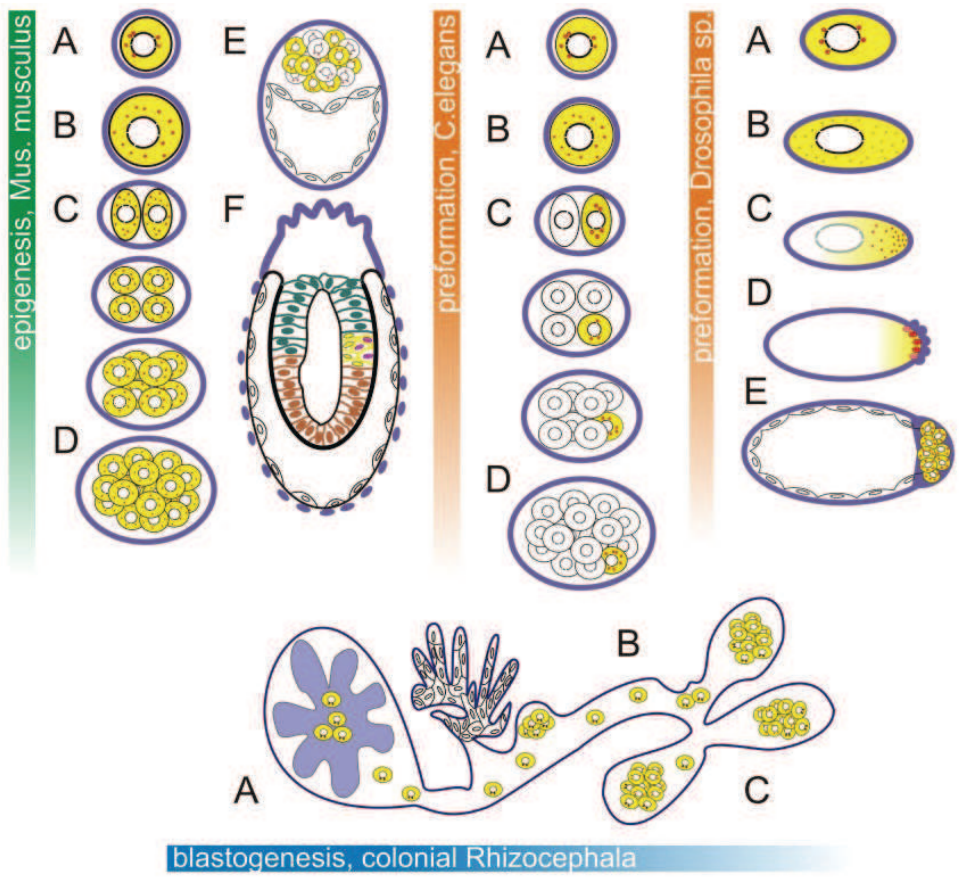

Fig. 1. Germline specification in Metazoa: epigenesis in mouse; preformation in C. elegans and Drosophila and blastogenesis in colonial Rhizocephala. Epigenesis and preformation: oocyte (A) with distinguished germ granules/germ plasm (red) by the nucleus; specific macromolecular complexes of cytoplasm (yellow), including proteins and transcripts of germline marker genes; mature egg or zygote (B), the germline granules presumably distribute evenly in the cell mass, in Drosophila the distinguished granules did not form yet; cleaving zygote (C-D), 2- to 16-cell blastomeres, maternal cytoplasm is distributing equally in mice and not equally in C. elegans, where only one blastomere inherited germ granules and the specific cytoplasmic factors, polarized cytoplasm in Drosophila, germ granules are located at the posterior pole; (E) in mouse, the group of pluripotent cells form the inner cell mass of the blastocyst, in Drosophila, germline cells specified by polarized germ granules; $(\mathrm{F})$ germline specification occurs inside epiblast during mesoderm formation. Blastogenesis: in colonial Rhizocephala, gametogenic stem cells (SC, yellow) within stolon migrate to the rudiment of the gonad of the developing blastozooid (A), forming a germline lineage (blue colour, differentiating somatic tissues), totipotent SCs of the tubular-like stolon (B) forming buds (C). 


\subsubsection{Morphological evidence of "nuage"/germ granules/chromatoid bodies}

"Germ plasm" (Keimplasma), Weismann's famous term, originally denoted the nuclear genetic material (Weismann, 1982, 1893) now is understood metaphorically as cytoplasmic compartment containing specific ultrastructural marker and a key organelle of metazoan germline cells (Amikura et al., 2001; Ikenishi, 1998; Lim \& Kai, 2007; Matova \& Cooley, 2001; Seydoux \& Braun, 2006). Perinuclear germinal granules are almost universal specific organelles of germ cells. The ultrastructure of these organelles is similar, but they can be represented in cells of different organisms as either granules (bodies) or as a cloud (nuage) of fine-dispersed material. There are various terms for the specific electron-dense material: germ plasm granules, nuage, germ cell granules, polar, perinuclear, chromatoid, germinal, germ granules (bodies), dense bodies, etc. (Eddy, 1975; Flemr et al., 2010; Ikenishi, 1998; Isaeva, 2010, 2011; Mahowald, 2001; Seydoux \& Braun, 2006; Lim \& Kai, 2007). Despite the various terms for the germline granule in different model species, several common features are found (Fig. 2). It seems that the morphological appearance of the structure is linked to stage-specific function and macro-molecular composition, which will be discussed later in this review.

Nuage/germ granules/chromatoid bodies are morphologically and ultrastructurally identifiable and similar to each other. They are discrete, electron-dense organelles, composed of fibrillar and granular material, not bounded by a limiting membrane, often located in the perinuclear cytoplasm and usually associated with clusters of mitochondria. These bodies are found in germ cells in many stages of development, ranging from primordial germ cells in embryos to gametes in adult gonads. The observations suggest that germ granules/nuage/ chromatoid bodies represent different forms of the same material over time (Eddy, 1975; Ikenishi, 1998; Kloc et al., 2004; Mahowald, 2001; Parvinen, 2005). Germ granules have been called by a variety of names reflecting their different morphology at different developmental stages and in different organisms, for example, $\mathrm{P}$ granules in Caenorhabditis elegans, polar granules in primordial germ cells and nuage during later development in Drosophila and other insects, Balbiani body and germinal granules in Xenopus, chromatoid body in mammalian male germ cells (Eddy, 1975; Extavour, 2008; Kloc et al., 2004; Seydoux \& Braun, 2006). Large complexes including other organelles as in Xenopus oocytes were called Balbiani body, mitochondrial cloud, intermitochondrial cement, yolk nucleus etc: the old nomenclature is "confusing and chaotic" (Kloc et al., 2004). The Balbiani body was also observed in oocytes of mouse (Pepling et al., 2007). Seydoux \& Braun (2006) used the generic term "germ granules" to refer to all these structures considered as hubs for posttranscriptional regulation of gene expression. While the various names of these structures correspond to differences in morphology, composition, and animals in which they were first identified, it is believed that they are related entities (Eddy, 1975; Gustafson \& Wessel, 2009; Parvinen, 2005). The exact relationship between all of these differently named structures has not been determined, but it is possible that they are all different morphological manifestations of the same germ line-specific body (Extavour \& Akam, 2003). The chromatoid body of mammalian spermatocytes and spermatids is also suggested to be a mammalian counterpart of nuage on the basis of its structural features and protein composition (Parvinen, 2005; Pepling et al., 2007). Accumulating evidence indicates that the chromatoid body is involved in RNA storing and metabolism, being related to the RNA processing body (P-body: see below) of somatic cells (Kotaja et al., 2006; Nagamori et al., 2011). Here we will refer to these structures as germ plasm related bodies (GPRBs). 
It was proposed that the determination of primordial germ cell fate in mammals is independent of germline-specific granules and occurs through an inductive process. Flemr and colleagues (2010) described the dynamics of the maternal stable untranslated transcripts (dormant maternal mRNAs) as components of P-bodies in mouse oocytes and reported that oocyte growth is accompanied by loss of P-bodies and a subcortical accumulation of several RNA-binding proteins, forming transient RNA-containing aggregates. The authors proposed that the cortex of growing oocytes contains a novel type of RNA granule related to P-bodies. Although early mouse oocytes contain granulo-fibrillar material reminiscent of germ cell granules in association with transiently appearing Balbiani bodies, later oocytes lack detectable germ granules (Flemr et al., 2010). Other authors argued that true P-bodies were not observed until the blastocyst stage of embryogenesis, providing evidence that mouse oocytes develop using molecular and developmental mechanisms widely conserved throughout the animal kingdom (Pepling, 2010; Pepling et al., 2007). Hubbard and Pera (2003) reasoned that basic germ-plasm machinery exists in mammalian germ cells as submicroscopic complexes. In many organisms, GPRBs associate with nuclear pores (Eddy, 1975; Seydoux \& Braun, 2006; Snee \& Macdonald, 2004). The nuage is visible traversing the nuclear pores, so there is high probability that all or some of the nuage components originate in the nucleus or shuttle between the nucleus and nuage (Kloc et al., 2004). Continuity in electron-dense material between the nucleus and the chromatoid body through nuclear pore complexes has also been observed in male germ cells (Parvinen, 2005; Updike et al., 2011). Polysomes have been reported adjacent to nuage in Drosophila (Mahowald, 2001), and chromatoid bodies in rats (Parvinen, 2005). Perinuclear nuage clusters have remarkably dynamic composition, despite their relatively fixed positions around the nucleus (Snee \& Macdonald, 2004). In the Xenopus oocyte and cleaving embryo, the germinal granules undergo constant transformation in size, number, and ultrastructure. Although the structure and behavior of germ line-specific structures show extraordinary variability, there are also striking similarities and common themes even among evolutionarily distant organisms (Kloc et al., 2004).

Thus, the presence of GPRBs with their specific organization and localization in the cell is an evolutionary conserved feature of metazoan germline cells. GPRBs have been found in more than 80 species of 8 animal types (Eddy, 1975). At least one new additional metazoan type can be added to Eddy's list - Porifera, because electron-dense bodies sometimes described as "nuclear extrusion" or "chromidia" were observed in oogonia and oocytes of several sponge species (see Harrison \& De Vos, 1991; Isaeva \& Akhmadieva, 2011). The germ granules, "the work horses" of germ cells, are thought to function as a specific cytoplasmic regulatory center, maintaining the genomic totipotency, preventing the expression of somatic differentiation genes, and protecting germline cells from somatic fate (Chuma et al 2006; Cinalli et al 2008; Extavour, 2008; Seydoux \& Braun, 2006; Srouji \& Extavour, 2011; Strome \& Lehman, 2007), preventing somatic fate "by default" (Leatherman \& Jongens, 2003).

\subsubsection{Molecular signature}

Germ granules and nuage contain products of marker germline genes, which are recognized as molecular signature of germline cells. GPRB's components include proteins, mRNAs, and noncoding RNAs. RNA-binding proteins in germinal granules are involved in mRNA localization, protection, and translation control. The molecular machinery and molecular 
signature of germline cell specification includes a set of evolutionary conserved proteins such as Vasa, Piwi/Aubergine, Nanos, Tudor, Pumilio, Staufen and some others whose homologues have been identified in all metazoans studied (Extavour \& Akam, 2003; Leatherman \& Jongens, 2003; Kloc et al., 2004; Parvinen, 2005; Chuma et al., 2006; Pepling et al., 2007; Lim \& Kai, 2007; Extavour, 2008; Gustafson \& Wessel, 2010; Flemr et al., 2010; Srouji \& Extavour, 2011). It was shown that some proteins of the germinal granules determine germ cell fate, and their genes are evolutionary conservative in all studied metazoans (Ikenishi, 1998; Matova \& Cooley, 2001; Mochizuki et al., 2001; Seydoux \& Braun, 2006; Srouji \& Extavour, 2011). Every known nuage component has a role in one or more types of posttranscriptional control of gene expression; the presence of shared components reinforces the notion that nuage and polar granules are closely related structures (Snee \& Macdonald, 2004). Genes related to vasa (vas) and other genes of the DEAD family (Raz, 2000; Shukalyuk et al., 2007) and to piwi/argonaute family (Funayama al., 2010) were found in a diverse range of eukaryotes from yeast to plants and animals; molecular and functional similarities of these genes were found across the kingdoms (Mochizuki et al., 2001; Watanabe et al. 2009). Products of the vasa- and piwi-related genes are the most widely used molecular germline markers for Metazoa (Extavour \& Akam, 2003; Ewen-Camden et al., 2010; Gustafson \& Wessel, 2010; Alié et al., 2011)

\subsubsection{Vasa, DEAD box family}

vasa protein of the Drosophila (or its homologues), germline-specific RNA helicase is a key determinant of the fate of germline cells found in GPRBs of germline cells across animal kingdom (Alié et al., 2011; Cinalli et al., 2008; Extavour \& Akam, 2003; Ewen-Camden et al., 2010; Gustafson \& Wessel, 2010; Shibata et al., 1999, 2010; Sroji \& Extavour, 2011; Sunanaga et al., 2006). Products of vasa-related genes are necessary for the formation and maintenance of the structural organization of GPRBs and, presumably, for the maintenance of pluri/totipotency of cells. Vasa and Pl10 are members of the DEAD-box family of RNA helicases, proteins known to function in all eukaryotes, from yeast up to plants and animals, in wide aspects of RNA metabolism, including unwinding double-stranded RNAs and controlling their export, splicing, editing, stability, and degradation. They are involved in ribosome biogenesis, translation initiation, and mediating both RNA-RNA and RNAprotein interactions, promoting expression of other germline genes (Cinalli et al., 2008; Gustafson \& Wessel, 2010).

The Vasa-like protein and a set of RNA-binding proteins, as well as other translational regulators are common and invariable components of GPRBs in many organisms. The presence of Vasa-like proteins in the germ plasm of different animals indicates the conservation of molecular mechanisms underlying the formation and maintenance of the germ plasm across Metazoa (Extavour, 2008; Ewen-Campen et al. 2010; Gustafson \& Wessel, 2010; Juliano et al., 2010; Kloc et al., 2004).

\subsubsection{Piwi, Piwi/Argonaute family}

Piwi/Argonaute family members serve as epigenetic regulators of stem cells in many systems. Piwi/Ago proteins are an animal germline-specific subclass, highly conserved across eukaryotes, specifically expressed in germ cells and playing a key role in germ cell maintenance and self-renewal, transposon silencing, and RNA silencing. These proteins are 
at the core of RNA-silencing machinery that uses small RNA molecules as guides to identify homologous sequences in RNA or DNA. The small RNAs regulate genes at the transcriptional or post transcriptional level affecting either chromatin structure or mRNA stability and mediating transcriptional gene silencing in germline maintenance (see Gustafson, Wessel, 2010; Peters, Meister, 2007; Thomson, Lin, 2009; Watanabe et al. 2009; Sroji \& Extavour, 2011). Particularly, chromatoid bodies in male germ cells seem to operate as "intracellular nerve centers" of the microRNA pathway and function as subcellular concentration sites for components of the miRNA pathway, centralizing the miRNA posttranscriptional control system in the cytoplasm of haploid male germ cells (Kotaja et al., 2006; Nagamori et al., 2011). There are important interactions between Piwi and Vasa in the germline. PIWI-mediated microRNA pathways are evolutionarily conserved control mechanisms, found in bacteria, archaea and eukaryotes and are essential for stem cell division in both animal and plant kingdoms (see Ewen-Camden et al., 2010; Funayama et al., 2010; Watanabe et al., 2009).

\subsubsection{Tudor-domain contained proteins}

tudor (tud) gene products of D. melanogaster are key components of polar granules and nuage (see Anne, 2010; Arkov et al., 2006; Chuma et al 2006). Tudor motifs are found in many metazoan organisms and have been indentified to play a role in protein-protein interactions in which methylated protein substrates bind to these domains. Tudor protein interacts in vitro with Valois, which is a component of the methylosome in Drosophila (Mahowald, 2001; Anne, 2010). It also was shown to play a role in barrel-like folding, which creates the ability to bind and to recognize methylated histone H3-K4 and H4-K20 for a double Tudor-domain protein in human (Huang et al, 2006). The Tudor domain of the SMN (survival motor neuron) protein binds directly to spliceosomal SM proteins during spliceosome assembly (Selenko et al., 2001).

Thus, germline cells are relatively transcriptionally quiescent during most of embryonic development. Moreover, germ cells are typically mitotically quiescent from the time of their specification during embryogenesis, until the time that gametogenesis begins, usually during larval or adult life (Extavour, 2008). The transfer of most of the control of gene expression to the cytoplasm is an important evolutionary conservative acquisition ensuring plasticity for the germ cell genome (Seydoux \& Braun, 2006).

\subsection{Pluri/multipotent gametogenic stem cells of asexually reproducing animals}

\subsubsection{Germ granules/chromatoid bodies}

In asexually reproducing invertebrates, stem cells capable of differentiating into germ and somatic cells can be identified by the presence of specific electron-dense cytoplasmic structures, morphologically similar or identical to germinal granules of germline cells (referring to GPRBs). In stem cells of asexually reproducing invertebrates, the germinal granules were revealed before our work in stem cells of cnidarians and flatworms. For example, the electron-dense bodies similar or identical to GPRBs of germline cells were found in interstitial cells of the hydra Pelmatohydra robusta. Bodies were associated with nuclear pores and mitochondria. The number and size of such dense bodies increased during early oogenesis and decreased during differentiation of somatic cells (cnidoblasts) from interstitial cells (Noda \& Kanai, 1977). Studying many species across Metazoa, we also found significant similarity in the morphology of electron-dense bodies or granules (Fig. 2). 
In planarians, electron-dense GPRBs were observed not only in germline cells but also in neoblasts. The chromatoid bodies in planarian neoblasts and germ cells are found near the nuclear envelope, in close proximity to mitochondria as well (Coward, 1974; Hori, 1982; Isaeva et al., 2005; Shibata et al., 1999). Nuage-like structures morphologically different from planarian chromatoid bodies were found in the flatworm Macrostomum lignano (Pfister et al., 2008). The chromatoid bodies in planarian neoblasts decrease in number and size during differentiation of somatic cells from neoblasts and disappear in completely differentiated cells, while in oogenic cells the chromatoid bodies were found during the entire life cycle (Hori, 1982; Shibata et al., 1999). These observations suggest that the chromatoid bodies are concerned with the cell totipotency maintenance (Shibata et al., 1999).

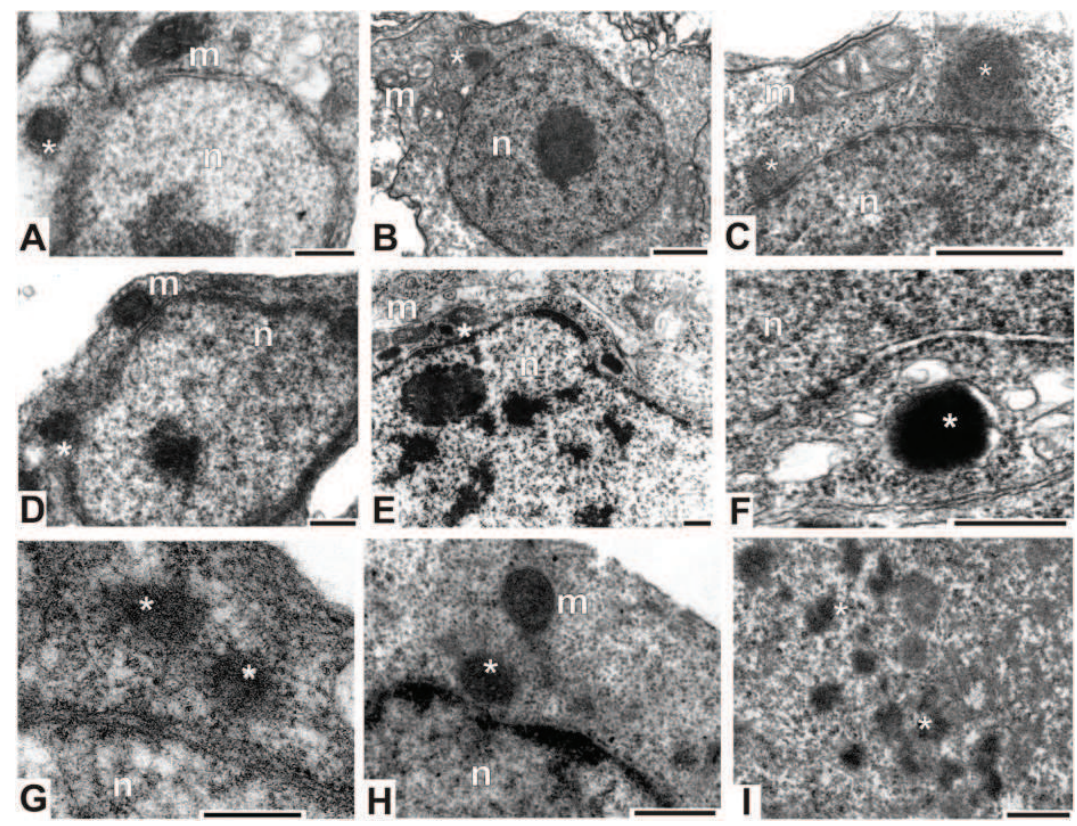

Fig. 2. Common morphofunctional feature of stem cells across Metazoa: transmition electron microscopic level of germ granules/nuage organization. Electron-dense granules $\left(^{*}\right)$ are usually localized near nucleus (n) pore and surrounded by mitochondira (m) in sponge Oscarella malakhovi (A, D and G), in planarian Girardia tigrina (E), in hydroids Ectopleura crocea (B and C) and Obelia longissima (F), as well as in mouse embryonic stem cells in culture $(\mathrm{H}$, embryoid body, day 1$)$ and in stem cells of inner cell mass of the mouse blastocyst (I). A, D and G, after Isaeva \& Akhmadieva, 2011; E, after Isaeva et al., 2005; F, after Isaeva et al., 2011; H and I, Shukalyuk et al., unbubl. Scale bar is $0.1 \mu \mathrm{m}$.

The morpho-functional organization of pluripotent gametogenic stem and gonial cells in studied representatives of diverse metazoan phyla shares with germ and stem cells common properties as described above. Particularly, in the cytoplasm of archaeocytes in the sponge Oscarella malakhovi we have found germinal granules of a typical morphology located near the nuclear envelope and surrounded with polysomes (Isaeva \& Akhmadieva, 2011). Electron-dense GPRBs were found earlier in the oogonia and oocytes of different sponges 
but have not been previously described in the archaeocytes or any other cells of sponges. We revealed electron-dense GPRBs in interstitial cells of the colonial hydroids Obelia longissima and Ectopleura crocea (Isaeva et al., 2011), similar to "dense bodies" of interstitial and germ cells in Pelmatohydra robusta (Noda \& Kanai, 1977) and cnidarian oocytes. The GPRBs surrounded by mitochondria and in contact with nuclear pores have been found near the nuclear envelope in neoblasts and gonial cells of the planarian Girardia tigrina (Isaeva et al., 2005). We revealed typical GPRBs in the cytoplasm of embryonic stem cells and stem cells of the colonial rhizocephalans, Peltogasterella gracilis and Polyascus polygenea (Shukalyuk et al., 2005, 2007, 2011). In the cytoplasm of some stem cells in the early buds of colonial ascidian Botryllus tuberatus we have found small electron-dense bodies (Akhmadieva et al., 2007), similar to disperse material of nuage, often found in vertebrates. Perinuclear electron-dense germinal granules often associate with the nuclear pore membrane and bear signs of mitochondrial origin, in particular, cristae of the inner mitochondrial membrane.

Pluripotent or multipotent gametogenic stem cells in all studied asexually reproducing animals belong to 5 animal types: Porifera, Cnidaria, Platyhelminthes, Arthropoda, and Chordata. They all feature the presence of the germinal granules similarly to germline cells. Evidently, the electron-dense germ granules are ultrastructural markers and key organelles both of metazoan germline and potentially gametogenic pluripotent stem cells of asexually reproducing invertebrates.

\subsubsection{Molecular signature in pluripotent gametogenic stem cells}

In asexually reproducing animals, both germ and pluripotent stem cells express evolutionary conserved germ cell markers such as products of genes related to vasa/pl10, piwi/argonaute, nanos, tudor as well as high activity of alkaline phosphatase (AP, Fig. 3) and telomerase (Extavour, 2008; Ewen-Camden et al., 2010; Funayama et al., 2010; Gustafson \& Wessel, 2010; Isaeva, 2010, 2011; Mochizuki et al., 2001; Shukalyuk et al., 2005, 2007; Sroji, Extavour, 2011). Specifically, vasa-related gene expression is characteristic not only of germline cells, but also pluripotent gametogenic stem cells involved in their determination and maintenance. Vasa expression as well as a high activity of AP and telomerase became the classic selective markers of these stem cells (see Isaeva, 2011; Mochizuki et al., 2001; Rinkevich et al., 2009; Shibata et al., 1999; Shukalyuk et al., 2007; Sköld et al., 2009; Sroji \& Extavour, 20110). In many of the invertebrates, such as cnidarians, acoels, planarians, annelids and colonial urochordates, expression of Piwi and Vasa are not restricted to the germline but are expressed in multipotent stem cells (Alié et al., 2011). Piwi is considered to be an omnipresent stemness flag for self-renewal and maintenance of germ line and stem cells in diverse multicellular organisms (Rosner et al., 2009). Several studies indicate a functional relationship between Vasa and both the small interfering RNA and micro-RNA processing pathways (Gustafson \& Wessel, 2010). In sponges, cnidarians, flatworms, and colonial botryllid ascidians, germ cells derive from adult pluripotent stem cells (Agata et al., 2006; Extavour, 2008; Isaeva, 2010; 2011; Rinkevich et al., 2009; Sköld et al., 2009; Srouji \& Extavour, 2011). Gametogenic potentiality was observed also for stem cells in colonial rhizocephalan crustaceans $P$. polygenea and P. gracilis; the stem cells migrated into the developing ovary becoming oogonial cells (Isaeva et al., 2004; Shukalyuk et al., 2005). 


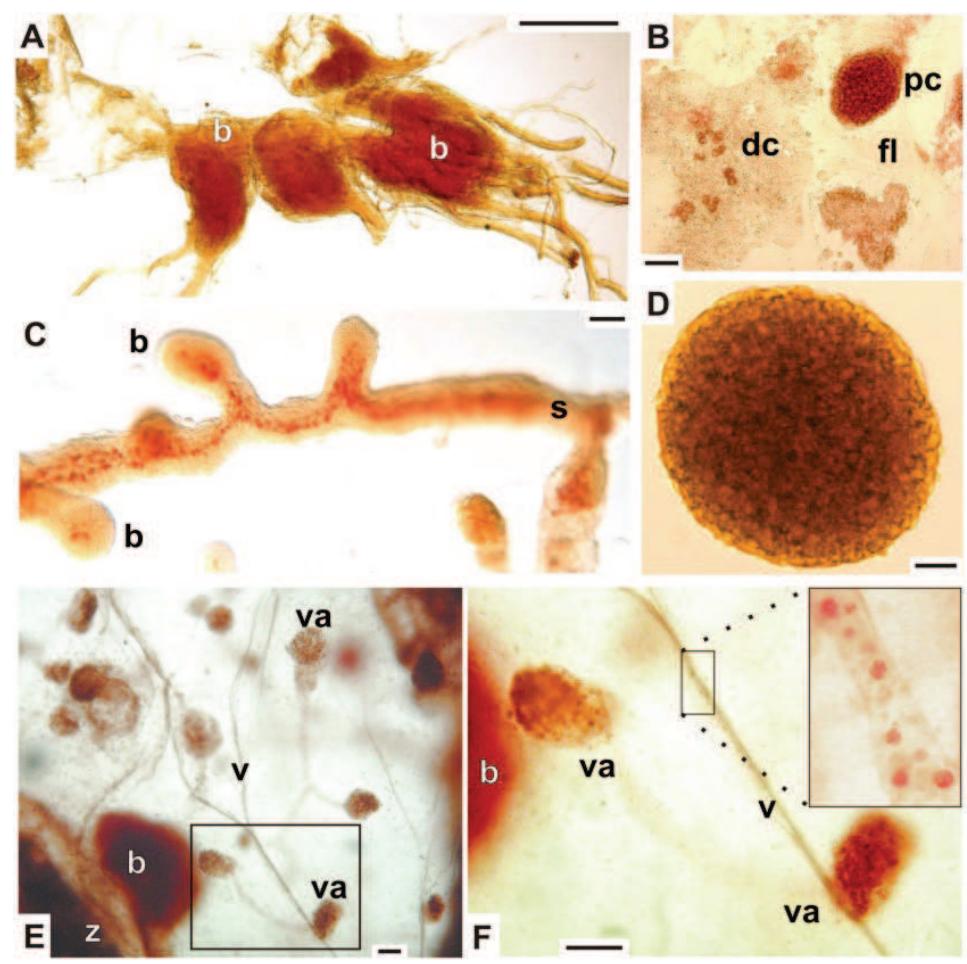

Fig. 3. Common histochemical feature of stem cells across Metazoa: selective expression of alkaline phosphatase (AP): A, buds (b) within a colony of Peltogaster reticulatus

(Rhizocaphala); B, high AP-reaction in pluripotent Mus musculus ESCs and low expression in their differentiated colonies (dc) or fibroblasts (fl); C, AP-positive stem cells inside stolon (s) and buds (b) of Peltogasterella gracilis (Rhizocephala); D, AP reaction in neurosphere of Mus musculus ESCs in culture; E and F (selected E), AP-positive hemoblasts of Botryllus tuberatus inside zooid (z), bud (b), vessel (v) with AP-positive hemoblasts (enlarge in F), and vascular ampulla (va) during vascular budding. A, B \& D, Shulalyuk, unpubl.; C, after Shukalyuk et al., 2005; D, after Akhmadieva et al., 2007. Scale bar is $20 \mu \mathrm{m}(\mathrm{B}, \mathrm{D}-\mathrm{F})$ \& 50 $\mu \mathrm{m}(\mathrm{A}, \mathrm{C})$.

In the freshwater sponge Ephydatia fluviatilis (Porifera), expression of piwi orthologues was found in sponge archaeocytes and choanocytes, sponge pluripotent gametogenic stem cells (Funayama, 2008; Funayama et al., 2010). The expression of nanos-, vasa- and PL10-related genes (Mochizuki et al., 2000, 2001) was demonstrated for the adult interstitial and germline cells for the hydrozoan Hydra magnipapillata (Cnidaria); piwi-like expression was found in germline and stem cells of the jellyfish Podocoryne carnea (Seipel et al., 2004). vasa-like gene expresses in interstitial stem cells of Hydractinia echinata (Rebscher et al., 2008). Piwi/Ago, Pumilio, PCNA were revealed in the hydrozoan Hydra magnipapillata and the anthozoan Nematostella vectensis, whereas orthologues of Oct4 and Nanog were not found (Watanabe et al., 2009). In the acoel Isodiametra pulchra (Acoelomorpha) expression of piwi orthologue was shown in germ cells and neoblasts (De Mulder et al., 2009). 
Planarian (Plathyhelminthes) neoblasts can differentiate into germ and somatic cells and express vasa, piwi, nanos, pumilio, bruno, tudor homologues (Agata et al., 2006; Pfister et al., 2008; Reddien et al., 2005; Rossi et al., 2007; Shibata et al., 1999, 2010; Solana et al., 2009). In Dugesia japonica two vasa homologues are expressed in the germ cells of the adult gonads. Only one of these homologues was expressed in neoblasts (Shibata et al. 1999). Flatworm vasa homologue of Macrostomum lignano was expressed in germ and stem cells (Pfister et al., 2008). Planarian homologues of piwi and pumilio genes were found specifically expressed in a neoblasts (Rossi et al., 2007) and the expression pattern of Piwi protein in planaria Schmidtea mediterranea coincides with the neoblasts (Reddien et al., 2005). The Tudor protein is a component of chromatoid bodies in germ cells and neoblasts in the planaria Schmidtea polychroa (Solana et al., 2009). Co-localization and co-expression of Piwi- and Tudor-related proteins also was detected in planarian neoblasts (see Shibata et al, 2010). In planarians, a high dose of irradiation significantly down-regulates neoblast's RNA metabolism, chromatin remodelling and transcription. However, a low dose of irradiation stimulates up-regulation of genes involved in signal transduction, cytoarchitecture organization, protein degradation, apoptosis, cell metabolism, intracellular trafficking and receptor/ligand activities (Rossi et al, 2007). Exposure to $\gamma$-irradiation demonstrates the presence of at least two irradiation-sensitive sub-populations of neoblasts in Schmidtea mediterranea (Eisenhoffer et al, 2008).
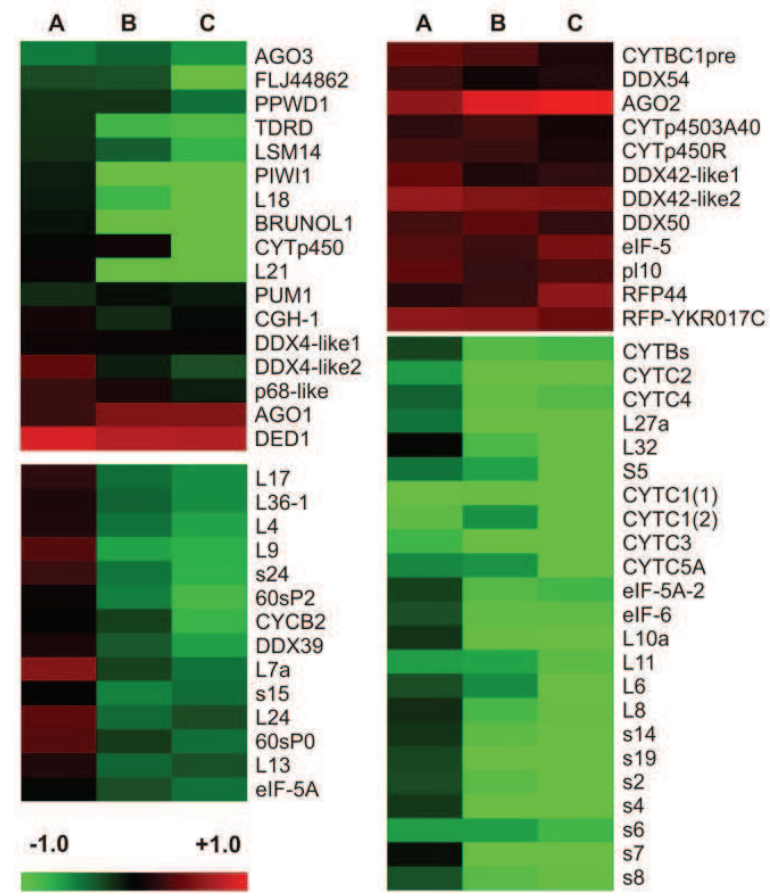

Fig. 4. Gene expression profile for neoblasts of planaria analyzed after irradiation at day 1 and day 7. Cluster analysis reveals set of genes which expression has changed slightly (right column) or dramatically (left column) from the level in wild type (A) to one day (B) or 7 days (C) post-irradiated animals. Heat map was generated using MultiExperiment Viewer v 4.3, emphasising gene expression in scale between -1.0 (bright green) and +1.0 (bright red). 
A significant decrease of expression was observed in genes involved in translation, RNA processing, and chromatin transcription, synthesis and repair corresponding to the population of cells affected after 1 day or 7 days post-irradiation. However, the second neoblast population, presumably slower proliferating and more restricted, demonstrate significant down regulation of a specific genes only on day 7 post-irradiation, corresponding to the function of energy production, mitochondria maintenance, translation, metabolism and others. piwi- (smedwl-1) and bruno-like (brunol-1) genes were down-regulated in both days, marking a totipotent sub-population of neoblasts. Transcripts of mitochondrial carrier, cytochrome p450, ribosomal L21 and L18 proteins were specific to the 7-day irradiated neoblasts. We used publicly available MicroArray data (NCBI GEO \#GSE11503; Eisenhoffer et al, 2008) to look at the expression profile of known components of germ plasm and nuage. In our analysis, we found it intriguing that as with Piwi1 and Brunol1 genes, expression of the tudor-like Tdrd gene was also down-regulated in both days post-irradiation (Fig. 4), as well as cytochrome C -family, L-family and S-family genes. However, high wild type expression of Ago2 up-regulated even more in both days post-irradiation, whereas Ddx42, Ddx50, and pl10 almost did not change in their expression (Fig. 4). In our opinion, mitochondrial cement might play an important role in gametogenic stem cell survival during specification by absorbing and utilizing some apoptotic factors that are released by mitochondria, such as cytochrome $\mathrm{C}$, and typically found in the germline germ plasm functioning as stress relief granules. It is conceivable that Tudor, Piwi, and Bruno homologues form the core structure of the germ plasm and present all the time within the dynamic structure, playing an important role in self-renewal and stem cell maintenance.

Pluripotent stem cells of colonial parasitic rhizocephalan barnacles (Rhizocephala: Cirripedia: Crustacea: Arthropoda) are predecessors of somatic and germ cells, thereby ensuring the reproductive strategy with alternation of asexual and sexual reproduction. The earliest blastozooid primordia arise as epithelial buds of stolon-like structures filled with migrating stem cells; there is a cluster of undifferentiated stem cells within each bud; later stem cells migrate as germ cells into developing ovaries (Isaeva et al., 2001, 2003, 2004; Shulalyuk et al., 2005). Earlier we revealed the evolutionarily conserved sites of vasa- and pl10- related genes of the DEAD family, in DNA of the rhizocephalan crustaceans Polyascus polygenea and Clistosaccus paguri (Shukalyuk et al., 2007). Selective expression of RNA of the vasa- and pl10-related genes was observed in pluripotent stem cells, in oogenic and spermatogenic cells (Shukalyuk et al., 2007). We also found selectively high activity of AP histochemical marker in stem cells of $P$. gracilis along with expression of proliferating cell nuclear antigen (PCNA) in interna (Isaeva et al., 2003; Shukalyuk et al., 2005). Recently, we have shown for P. gracilis the presence of Piwi, Vasa and Nanog proteins in pluripotent stem cells, early blastozooids and early rudiments of the trophic system (Sukalyuk et al, 2011; Shukalyuk \& Isaeva, unpubl. data).

Colonial ascidians (Chordata) can reproduce asexually, particularly, by palleal or vascular budding. In vascular budding of botryllid ascidians, pluripotent hemoblasts form buds generating a new individual. Hemoblasts are undifferentiated cells that can give rise to differentiated blood cells, somatic tissue cells of blastozooids during asexual reproduction, and evidently also to germline cells (see Rinkevich et al., 2009). Vasa-like gene expression was demonstrated in primary germline cells morphologically indistinguishable from hemoblasts in ascidian Botryllus primigenus (see Sunanaga et al., 2007). Brown and Swalla (2007) compared vasa-related gene expression in the solitary ascidian Boltenia villosa and the colonial ascidian Botrylloides violaceus. In B. villosa, mRNA of vasa-related gene was 
expressed in germ cells whereas mRNA of vasa-related gene of the ascidian B. violaceus in mature colonies was expressed in germ cells, in some circulating in the blood cells, in differentiating buds and zooids. Gustafson \& Wessel (2010) reported Vasa mRNA expression in germ lines along with hemoblast aggregates in Botryllus primigenus and Polyandrocarpa misakiensis. In the colonial Botryllus schlosseri, mRNA and the proteins of vasa, Pl10-, piwi- and Oct4- orthologues are not expressed exclusively in germ cell lineages, but emerging de novo also in circulating hemoblasts, thus indicating somatic embryogenesis (Rosner et al., 2009). The results strongly suggest that germline hemoblasts are recruited from undifferentiated hemoblasts in budding tunicates (Rosner et al., 2009; Sunanaga et al., 2007). Data on marker gene expression in gametogenic stem cells of colonial ascidians and their interpretation are rather contradictory (see below).

Pluripotent stem cells in various invertebrates with asexual reproduction as well as cells of the germ lineage display the expression of conserved genes related to vasa, piwi and others which function in the specification and maintenance of both cell types across different metazoan phyla (Agata et al., 2006; Gustafson \& Wessel, 2010; Juliano \& Wessel, 2010; Rinkevich et al., 2009; Sköld et al., 2009; Srouji \& Extavour, 2011; Wu et al., 2011). Besides the default characteristics of undifferentiated cells, these stem cells contain electron-dense perinuclear germ granules and express germline marker genes demonstrating that pluripotent stem cells display all of the morphological and functional features commonly used to identify germ cells.

\subsection{Mammalian embryonic stem cells via germline connection}

Embryonic stem cells (ESCs) are derived from the inner cell mass (ICM) of the developing embryo. During their adaptation for culture conditions these cells or some population of the originally extracted cells will gain some new properties and will become some sort of an artificial system. First, this adaptation includes the cell's ability to attach to the supporting surface: tissue culture treated plastic, extracellular matrix or feeder layer. Second, highly proliferating cells will be selected over time with self-renewing capacity. Third, cells that are selected within the culture will be responsive to the cell culture medium signaling, for example, from serum supplements and LIF (Leukemia Inhibitory Factor) for mouse ESCs or basic FGF (Fibroblasts Growth Factor) for human ESCs. However, it is commonly accepted that the ICM cells of the embryo are pluripotent cells equal in their properties to ESCs in culture, and can recapitulate normal embryonic development in vitro when placed under specific conditions.

\subsubsection{Nuage/germ granules}

The inner mass cells of mammalian embryos in vivo contain P-bodies (Pepling et al., 2007; Pepling, 2010), but we do not know any data in the literature on P-bodies, nuage or germ granules for embryonic stem cells cultured in vitro. As Clock and coauthors (2004) wrote, it will be interesting to see whether the embryonic stem cells in mice contain chromatoid body similar to that present in totipotent cells in planarians. We were the first to report morphological evidence for electron-dense germinal granules and more dispersed nuage material located near the nuclear membrane in the cytoplasm of mouse EMCs in vitro using confocal and light microscopy, with localization of mouse vasa homologue DDX4/MVH in perinuclear granules or nuage (Shukalyuk, 2009). 


\subsubsection{Molecular signature}

In pluripotent mammalian ESCs, molecular signature and a core transcriptional regulatory network dedicated to establishment and preservation of pluripotency include a set of marker genes overlapping with gene signature of germline cells (Kim et al., 2008). The transcription factors Nanog, Oct4 and Sox2 are considered to be the core of the transcriptional network involved in pluripotency and commitment in human or mouse ESCs and have been recognized to be essential in vivo and in vitro for early development and coordinately regulating the epigenetic network supporting ES cell pluripotency (see Chambers et al., 2003; Do \& Schöler, 2009; Jaenisch \& Young, 2008; Kim et al., 2008; Rosner et al., 2009; Seydoux, Braun, 2006; Stice et al., 2006; Walker et al., 2007). Moreover, Oct4, Sox2 and Nanog can also indirectly regulate gene transcription by affecting chromatin structure, DNA methylation, microRNA and $X$ chromosome inactivation, changes in local and higher order conformation of DNA, and RNA interference; so, Oct4, Sox2 and Nanog are involved in the cellular machinery, which has an important role in cell fate determination (Atkinson \& Armstrong, 2008; Do \& Schöler, 2009).

Nanog is a transcription factor, homeodomain protein found in mammalian pluripotent ES and developing germ cells, essential for mammalian embryogenesis. Nanog is thought to be a key factor underlying pluripotency in early development and ESCs, maintaining selfrenewal of ESCs and developing germ cells. Nanog is considered a core element of the transcription network and regulatory circuits underlying pluripotency and reprogramming, a hallmark of pluripotent cells in vivo and in vitro (Do \& Schöler, 2009; Stice et al., 2006; Jaenisch \& Young, 2008; Kim et al., 2008; Watanabe et al. 2009). Both Nanog and Oct4 are not expressed in mammalian somatic stem cells and loss of Nanog is an early marker of differentiation (Do \& Schöler, 2009).

Previously we reported (Shukalyuk \& Stanford, 2008) as others have mentioned (LachamKaplan, 2006) that some germline related genes are spontaneously expressed in mouse ESCs and reprogrammed mouse induced pluripotent stem cells (iPS) (Shukalyuk, 2009), even when cultured under the pluripotent and self-renewing condition maintained with LIF. We also found that the mouse homologues of Vasa (Ddx4), Stella, Dazl, Piwi (Miwi) and p68 $(\mathrm{Dd} \times 5)$ can be found in a surprisingly similar proportion of the cells in various ESC lines. We also observed reorganization of proteins and their accumulation in granules visible under confocal microscope after $72 \mathrm{hrs}$ of initiating spontaneous differentiation by withdrawing LIF. We showed the co-localization of DDX4 protein with mitochondrial cytochrome C oxidase IV (COX IV) and single strand binding protein (SSPB1) in germ-like perinuclear granules of mouse ESCs. We also demonstrated that among others, Stau1 and Stau2, mRNA of staufen-related genes, were significantly enriched in ESC's RNA using immune-precipitation with anti-mDDX4 antibody (Shukalyuk, 2009).

Using a publicly available on-line micro array data set (NCBI GEO \#GSE7506, Walker et al, 2007) we focused on the expression profile of germ-plasm related genes in mouse ESCs under pluripotent culture condition (LIF plus) and during spontaneous differentiation without LIF (LIF minus) or direct differentiation under retinoic acid treatment (RA plus). It is known that embryonic stem cells in culture are heterogeneous in their level of pluripotency marker expression. 


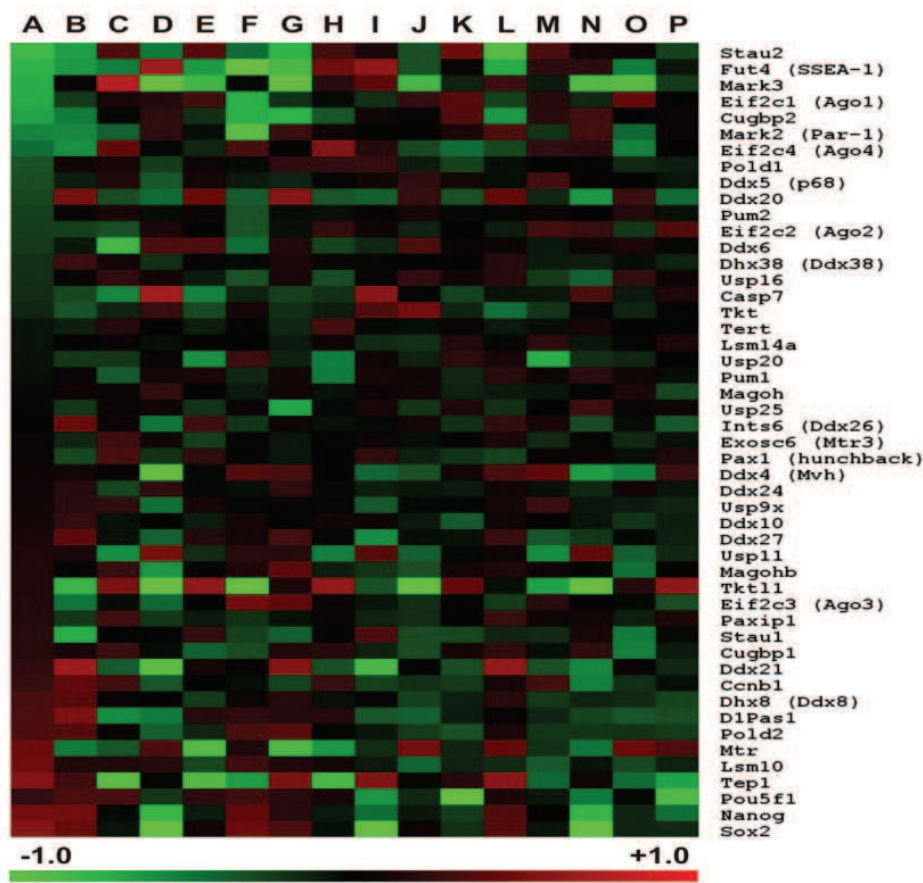

Fig. 5. Gene expression profile for OCT4-high (H), -medium (M) and -low (L) sub-populations of mouse ESCs differentiating over time under LIF- (5 days) or RA+ (2 days) conditions. Day0: A, LIF+(H); F, LIF+(M). Day1: B, LIF-(H); E, RA+(H); G, LIF-(M); J, RA+(M); L, LIF-(L); O, RA+(L). Day2: K, RA+(M), P, RA+(L). Day3: C, LIF-(M); H, LIF-(M), M, LIF-(L). Day5: D, LIF(H); I, LIF-(M); N, LIF-(L). Heat map was generated using MultiExperiment Viewer v 4.3, emphasising the scale between -1.0 (bright green) and +1.0 (bright red).

In this particular data set, mouse ESCs were sorted based on their high, medium and low OCT4 (POU5F1) protein expression and each sub-population (high, medium and low) was differentiated under LIF-minus or RA-plus condition. As expected (Fig. 5), expression of Oct4, Sox2 and Nanog decreased overtime in each sub-population under both differentiating conditions. Expression of the Ddx4 gene, as compared to other DEAD-box contained genes (Ddx5, Ddx6, Ddx8, Ddx10, Ddx20, Ddx21, Ddx24, Ddx27), gradually increased, peaking on day 3, and dramatically decreased in each population by day 5 under LIFminus condition. An increase in Ddx4 expression was also observed for OCT4-low and OCT4-medium sub-populations of ESCs by day 2 under RAplus treatment (Fig. 5). Upregulation of Ddx4 gene expression by day 3 during spontaneous differentiation is directly correlated with the same trend of Stau2, Eif2c4 (Ago4), Eif2c2 (Ago2), Eif2c1 (Ago1), Lsm14a and p68 (Ddx5) gene expression for all sub-populations but not for Stau1, Eif2c3 (Ago3) or Lsm10. Remarkably, significant down-regulation of germ-plasm members such as Ddx4, Stau2, Ago-family, p68 and Lsm14a oppositely correlates with Casp7 gene expression which is down-regulated at day 3 but significantly up-regulated by day 5 in all ESC populations (Fig. 5). A quick switch over time between levels of expression was indentified for mictotubule affinity-regulating kinase Mark3, as well as for telomerase associated Tep1 gene 
and Tktl1, a known catalytic metal ion binding gene. These data are in line with existing Drosophila germ plasm composition studies revealing the presence, among transcriptional control regulators (Bruno, Nanos and Orb), of zinc ion binding and $\mathrm{Ca}^{2+}$ signaling element (Rangan et al., 2009). DDX4 is a DEAD-box family protein that, along with Oct4 and Nanog gene products, can express in the ICM, primordial germ cells (PGS) and ESCs (Chambers et al., 2003; Stice et al., 2006; Zwaka, Thomson, 2005). In undifferentiated mouse embryonic and induced pluripotent stem cells, we found expression of Ddx4/Vasa, Miwi/Piwi, Nanog and Oct4 (Shukalyuk, 2009). Futhermore, Oct4 expression appears to be crucial for the PGCs function and survival. Loss of Oct4 leads to the PGCs apoptosis in mammalians, instead promoting expected trophectodermal differentiation (Kehler et al., 2004).

Mammalian pluripoitent ESCs capable of differentiating into female and male germ cells in vitro are potentially gametogenic cells (Clark et al., 2004; Eguizabal et al., 2009; Mathews et al., 2009; Toyooka et al., 2003), along with invertebrate pluripotent stem cells. Because mammalian ESCs are capable of differentiating into germ cells, this suggests that these cells in mice contain all necessary components for the determination of germ cell fate and they are totipotent, despite their lack of differentiating towards extra-embryonic tissue. Observation of the common expression for protein and mRNA mammalian markers in both PGCs and ESCs has led to the hypothesis that embryonic stem cells are closely related, or even identical, to early germ cell precursors (Clark et al., 2004; Fox et al., 2007).

\subsection{Evidence of de novo inducibility for germline markers}

Generally, germline cells can be identified and retraced during development of an organism due to the availability of molecular markers. However, the molecular signature of pluripotent gametogenic stem cells becoming germline cells is not always and necessarily continuous during development and germline specification.

De novo epigenetical specification of hemoblasts into female germ cells was described in the colonial tunicates Botryllus primigenus and Polyandrocarpa misakiensis (Sunanaga et al., 2007; Rosner et al., 2009). In B. primigenus, vasa homologue expressing cells within the loose cell mass of the primary germline cells evidently arose from the vasa-negative cells at postembryonic stages. These results show that germ cell specification is inducible de novo. It has been suggested that germ cell formation in B. primigenus is a consequence of epigenetic induction during zooid differentiation. Similarly, in another budding ascidian, P. misakiensis, a vasa homolog was expressed strongly by loose cell aggregates and germ cells, indicating that germ cells arise de novo in developing zooids and suggesting that the vasa homologue plays a decisive role in switching the cell fate from coelomic stem cells to germ cells (Sunanaga et al., 2007). In Botryllus schlosseri, Vasa detected from the larva and the oozooid stages, repeatedly emerge de novo in the colony, independently of its sexual state (Rosner et al., 2009). The expression of Pl10-, -piwi- and Oct4- orthologues both in germline cells and also in circulating pluripotent stem cells, hemoblasts, in B. schlosseri in contrast to the observations in B. primigenus and P. misakiensis might reflect different modes of germ lineage sequestering between the species (Rosner et al., 2009). During development of the ascidian Ciona intestinalis, primary germ cells are localized to the tail of the tadpole and during metamorphosis migrate into the adult gonad rudiment. If the tail with primary germ cells is removed, adults still form mature germ cells, suggesting a compensatory mechanism that regulates ascidian germ line formation at a later ontogenetic stage (Takamura et al., 2002). In embryogenesis of the sea urchin Strongylocentrotus purpuratus, germ line determinants 
accumulate in the small micromere lineage. Vasa protein is enriched in the 16-cell stage micromeres and subsequent small micromeres. Experimental removal of Vasa-positive cells induces Vasa expression de novo in adjacent blastomeres (Voronina et al., 2008).

\subsection{Transient expression of germline marker genes during development and cell differentiation}

Among cnidarians, in Hydra magnipapillata, pl10 mRNA is expressed not only in undifferentiated cells (multipotent interstitial stem cells and germline cells) but also in differentiating somatic cells of the interstitial cell lineage. One of two vasa-related genes appears to be expressed in all kinds of undifferentiated cells: multipotent stem cells, germline cells and the ectodermal epithelial cells in the body column. However, none of the vasa/PL10 genes were expressed in fully differentiated somatic cells in Hydra (Mochizuki et al., 2001). Analyses of the piwi-related gene during embryogenesis and medusa formation in the hydrozoan Podocoryne carnea have shown this gene expression in somatic stem cells as well as the germ line cells (Seipel et al., 2004). In sea anemone Nematostella vectensis (Cnidaria) members of the vasa and nanos families are expressed not only in presumptive germline cells but also in broad somatic domains during early embryogenesis and later are restricted to primary germ cells (Extavour et al., 2005).

During embryonic development of the planaria Schmidtea polychroa, Tudor-related protein is expressed in differentiating cells rather than neoblasts (Solana et al., 2009).

In the larvae of polychaete annelid Platynereis dumerilii, piwi-, vasa-, PL10- and nanos-related genes are expressed altogether at the mesodermal posterior growth zone in highly proliferative stem cells providing the somatic mesoderm and the germ line. vasa-like gene expression was revealed in the germ line as well as in multiple somatic tissues, including the mesodermal bands, brain, foregut, and posterior growth zone (Rebscher et al., 2007). During embryonic development of the oligochaete annelid Tubifex tubifex, transient vasa homologue expression was observed in cells in nongenital segments (Oyama \& Shimizu, 2007). In polychaete Capitella sp. during embryonic, larval, and juveniles stages, vasa and nanos orthologues are coexpressed in somatic and germ line tissue. Both these genes reveals expression in multiple somatic tissues with largely overlapping but not identical expression patterns; following gastrulation, expression is observed in the presumptive brain, mesodermal bands, and developing foregut (Dill \& Seaver, 2008).

In various sea urchin species, Vasa, Nanos, and Piwi are expressed in descendants of the small micromeres and subsequently become restricted to the coelomic pouches, from which the entire adult rudiment will form, suggesting that these conserved molecular factors are involved in the formation of multipotent progenitor cells that contribute to the generation of the entire adult body, including both somatic and germ cells (Juliano et al., 2010; Voronina et al., 2008). In addition, echinoderm species lacking small micromeres, such as sea stars, also have Vasa protein and/or transcripts enriched in the larval coelomic pouches, suggesting a conserved mechanism for the formation of multipotent progenitor cells in the coelomic pouch to produce an adult rudiment within the echinoderms (Juliano \& Wessel, 2010; Wu et al., 2011). In the colonial ascidian Botryllus schlosseri, Pl10, piwi and Oct4 orthologues are highly expressed in differentiating soma cells (Rosner et al., 2009). In the cephalochordate amphioxus Branchiostoma floridae (Chordata), Vasa and Nanos, in addition to the early localization of their maternal transcripts in the primary germ cells, are also expressed 
zygotically in the tail bud, which is the posterior growth zone of highly proliferating somatic stem cells (Wu et al., 2011).

The data indicate a close relationship between presumptive germline cells and multipotent somatic stem cells during development (Wu et al., 2011) and suggest a common origin of germ cells and of somatic stem cells, which may constitute the ancestral mode of germ cell specification in Metazoa (Rebscher et al., 2007). A two-step model of germ cell specification was proposed as an ancestral mechanism involving co-specification of germ cells and stem cells: setting aside a population of undifferentiated pluripotent stem cells, which is excluded from somatic differentiation and has the potential to form both somatic and germ cells, from which the primary stem cells are segregated later (Rebscher et al., 2007).

\subsection{Germline marker features beyond gametogenic stem cells}

\subsubsection{Processing bodies and cytoplasmic RNA granules in somatic cells}

In eukaryotic somatic cells, mRNA metabolism is regulated by ribonucleoprotein (RNP) aggregates, RNP granules considered as possible equivalents of germ granules in germline cells. Post-transcriptional processes have a central role in the regulation of eukaryotic gene expression, and these processes are not only functionally linked, but are also physically connected by cytoplasmic granules (Eulalio et al., 2007). Cytoplasmic RNP granules function in determining mRNAs degradation, stabilization, intracellular localization, translational repression and RNA-mediated gene silencing. All RNA granules harbor translationally silenced mRNA. There are several classes of cytoplasmic granules in somatic cells named processing bodies (P-bodies, or P bodies), RNA or RNP granules, RNP particles, stress and neuronal granules (Anderson \& Kedersha, 2006; Eulalio et al., 2007; Flemr et al., 2010; Lachke et al., 2011; Kiebler \& Bassell, 2006; Kotaja et al., 2006; Seydoux, Brown, 2006).

In mammalian cells, P-bodies are the most common type of RNA granules and contain products of gene orthologues in germ cell granules (Flemr et al., 2010; Pepling, 2010). Processing bodies contain components of mRNA decay processes and microRNA-mediated silencing, serving as sites where mRNAs can be either stored or degraded (Kiebler \& Bassell, 2006; Lachke et al., 2006). Argonaute proteins, and also miRNAs and miRNA-repressed mRNAs, were demonstrated to localize in P bodies in mammalian cells.

Unlike P bodies, stress and neuronal granules contain ribosomal subunits. Stress granules are dense aggregates accumulated in cells in response to environmental stress and regulated translational repression and mRNA recruitment to preserve cell integrity. Neuronal granules deliver mRNAs and inactive ribosomes to specific translation sites in dendrites (Anderson \& Kedersha, 2006; Seydoux \& Brown, 2006; Flemr et al., 2010). In mammalian neuronal cells, three classes of RNA granules were described: transport RNP particles, stress granules, and $\mathrm{P}$ bodies with potential functions in RNA localization, microRNA-mediated translational regulation, mRNA degradation, and localized translation of mRNAs involved in synapse formation or motility (Anderson \& Kedersha, 2006; Kiebler et al., 2006). Electron dense perinuclear chromatoid body-like structures surrounding the nuclei of neurons were observed in the planaria Dugesia japonica (see Shibata et al., 2010).

Cytoplasmic RNP granules function in the posttranscriptional control of gene expression, but the extent of their involvement in developmental morphogenesis is unknown. Recently, a 
Tudor domain-containing RNA binding protein (TDRD7) was identified as a component of a unique class of RNP granules with a conserved pattern of developmental expression in ocular lens fiber cells (Lachke et al., 2011). Furthermore, human TDRD7 mutations result in cataract formation via the misregulation of specific, developmentally critical lens transcripts. TDRD7 perturbation causes cataracts in chickens and mice. TDRD1, TDRD6, and TDRD7 have been associated with chromatoid bodies in mammalian male germ cells. Tdrd7 null mutant mice develop cataract and glaucoma; an arrest in spermatogenesis also was observed. Staining with the antibody of STAU1, a mammalian homologue of the Drosophila RNA-binding protein Staufen, revealed the presence of numerous STAU1-positive RNP particles in lens fiber cells co-localized to a high degree with TDRD7. The authors hypothesized that TDRD7 granules, either alone or through their interaction with STAU1- RNP granules and P bodies, might regulate the expression levels of specific lens transcripts (Lachke et al., 2011).

Several P body markers are highly concentrated in chromatoid bodies (Kotaja et al., 2006). These data suggest that the chromatoid bodies of male germ cells and P-bodies in somatic cells are functionally related, both acting as a site for mRNA decay and mRNA translational repression by the miRNA pathway (Anderson \& Kedersha, 2006; Kotaja et al., 2006). Pbodies contain components of the RNA-dependent silencing machinery (Seydoux \& Braun, 2006). P-body components are also present in two other classes of somatic RNP particles: stress granules and neuronal granules (Anderson \& Kedersha, 2006). P-body components represent an ever-growing list of proteins involved in RNA metabolism, and the composition of P-bodies, stress granules in somatic cells and germ cell granules overlaps to some extent (Flemr et al., 2010). The data provide evidence of diversity of mammalian RNA granules. Although, they exhibit overlapping composition but different structures and functions (Flemr et al., 2010) sharing components and evolutionary conserved mechanism of post-transcriptional regulation with germ granules which function is distinguishably unique (Seydoux \& Braun, 2006).

\subsubsection{Germline marker gene expression in somatic stem pools and neurons}

Among asexually reproducing animals, vasa- and PL10-related genes are expressed in somatic ectodermal epithelial cells (unipotent stem cells) in the hydrozoan Hydra magnipapillata (Mochizuki et al., 2001). In the colonial ascidians Botryllus schlosseri, vasarelated gene products are not exclusively expressed in germ lineages but also are strongly expressed in many embryonic and bud somatic cells. Expression of vasa and piwi orthologues were detected in somatic tissues and Oct4-related gene was also expressed in the somatic cells of the endostyle (Rosner et al., 2009).

Among animals without asexual reproduction, piwi, vasa, and pl10 are expressed in somatic stem cells at the base of the tentacle bulb, giving rise to tentacle nematocytes in the hydromedusa (Cnidaria) Clytia hemisphaerica (Denker et al., 2008). Their expression, along with bruno orthologue, was found in germline cells in pluri/multipotent somatic stem cells in the tentacle root in Pleurobrachia pileus (Ctenophora), a species which reproduces only sexually (Alié et al., 2011). There is no experimental proof that ctenophore somatic stem cells are incapable of producing germ stem cells, but under normal conditions, this seems highly unlikely (Alié et al., 2011). There are also some other examples of canonic germline marker expression in somatic cells and tissues in bilaterian animals including vertebrates (see Alié et al., 2011; Gustafson \& Wessels, 2010; Wu et al., 2011). 
These data suggest two alternative hypotheses (see Alié et al., 2011). First, these genes are fundamentally associated with germinal potential, and when they are expressed in pluri/multipotent stem cells, they have the potential to generate germ cells. Second, these genes are components of an ancestral molecular toolkit of animal stem cells, whatever the fate of their progeny. Presumably, piwi, vasa and pl10 belong to a gene network ancestrally acting in two contexts: germline and pluri/multipotent stem cells. Since the progeny of these multipotent stem cells includes both somatic and germinal derivatives, it remains unclear whether vasa, piwi, and pl10 were ancestrally linked to stemness, or to germinal potential. Probably, total or partial restriction of these genes to the germline in some bilaterian groups (e.g., vertebrates and insects) is a derived, evolutionary secondary condition, and it is not appropriate to use these genes, including vasa, as germline markers (Alié et al., 2011). The fundamental reason why these genes are ancestrally linked to stemness, in addition to the germline, is probably the main function of the Piwi-piRNA pathway, i.e., genome protection through silencing. Genome protection is a crucial requirement not only for germ cells but also for somatic stem cells, and ancestral involvement of the same gene set in both the germline and somatic stem cells does not particularly imply their common origin in a genealogical sense, but the requirement of the same silencing pathway in two different contexts (Alié et al., 2011). Several conserved molecules are expressed in both germ cells and all types of stem cells (Sroji \& Extavour, 2011).Tthe piwi gene family may represent the first class of genes with a common molecular mechanism shared by diverse stem cell types in diverse organisms (Cox et al., 1998).

There are some data on relationship of pluripotent stem cells and neuroblasts. Some proteins classically related to germ line development have been recently found to be involved in neuronal function and development. In the planaria Schmidtea polychroa, Tudorrelated protein is expressed, beyond germline cells and neoblasts, in the central nervous system (Solana et al., 2009). pumilio and bruno planarian homologues are expressed similarly in neoblasts and in the central neural system, in perinuclear particles surrounding the nuclei of neurons (Salvetti et al., 2005; Guo et al., 2006). nanos and pumilio are involved in neuronal excitability, dendrite morphogenesis, and long-term memory in D. melanogaster (see Muraro et al., 2008; Solana et al., 2009). When mouse ESCs were cultured in serum- and feederdeprived conditions colony-forming primitive neural stem cell populatiuons could be obtained (Stice et al., 2006). Tropepe and coauthors (2001) proposed neural fate specification from ESCs by a default choise.

All the data suggest that primordial germ cells can be segregated at almost any point during embryogenesis: before blastoderm formation; after embryonic rudiment formation but before germ layer separation; after germ layer separation but before gonadogenesis; or after gonadogenesis and continuously throughout adult life (Extavour \& Akam, 2003).

\subsection{Regulatory gene networks underlying gametogenic potential and pluripotency}

The metazoan development program may be imagined as translation regulatory cascades. The regulatory transcriptional network to maintain stem cell function has been conserved during metazoan evolution (Watanabe et al., 2009). Genes vasa/pl10, piwi/auberdine, nanos, tudor, pumilio, and staufen, representing the core of the germline program, show striking evolutionary conservation (Alié et al., 2011; Chuma et al., 2006; Ewen-Camden et al., 2010; Extavour, 2008; Gustafson \& Wessel, 2010; Leatherman \& Jongens, 2003; Parvinen, 2005; 
Sroji \& Extavour, 2011). This gene network consists of gene modules whose interactions are highly stable and highly evolutionary conserved operating in similar ways both in different organisms, and in different places and/or times during the development of an animal organism. Interactions between vasa and other germ line genes have suggested a complex network of positive and negative regulation at multiple levels, including transcription, translation, and post-translational modification, epigenetic control of chromatin architecture mediated gene regulation crucial for the role in development (Cinalli et al., 2008; EwenCamden et al., 2010). Conserved germ cell-specific RNA networks repress transcriptional programs for somatic differentiation and promote germ cell maintenance (Cinalli et al., 2008). Maelstrom was identified as a nuage component that interacts with both mouse DDX4 and MIWI. It is required for spermatogenesis and also is involved in silencing transposable elements. Although still not definitive, the consistent association in multiple animals of Vasa and members of the RNAi pathway provides a strong argument that they have a functional relationship (Gustafson \& Wessel, 2010).

We took adventage of the bioinformatic tool STRiNG (Snel at al, 2000) to construct and analyze germ plasm protein network. Using Drosophila known germ plasm components (Fig. 6A) and their homologues in mouse (Fig. 6B), we predicted interactions and indentified several pathways based on the protein functional domains, structure and sequence similarity (Fig. 6D). Similar to Drosophila, known germ plasm proteins (Ddx4, Tdrd1, Tdrd7, Tdrd9, Pum2, Nanos1, Nanos2, Nanos3 and others) formed a network (Fig. 6D) responsible for germline differentiation (module 3 ) upon RNA processing via sequence-specific RNAbinding, translation and mRNA-stabilisation (1, 4: Pum1, Nanos2, Pum2) as well as normal mRNA turnover and nonsense-mediated mRNA decay (15: Dcp1a, Dcp2, Edc3, Edc4). Some other important germline related functions are revealed: transposable element repression by piRNA machinery during spermatogenesis (5: Piwi-family, Mael, Tdrd6 and etc), RNAmediated gene silencing (RNAi) by a RISC complex (2: Dicer1, Eif2-family/Ago2), translational activation of mRNA in the oocyte and early embryo $(16,17$ : Ddx3y, Ddx3x), and X-chromosome inactivation (8: Xiap). Several functions were related to molecular metabolism catalyzing the transsulfuration pathway from methionine to cysteine (20: Tdrd5, Cbs, Cth, Mthr-family), ribosomal protein complex (18: Mrps12, Mrps7, Mrpl11, Mrpl12, Rps20), proteasomal degradation and inhibition of the caspases (7, 8: Apaf1, Xiap, Casp7, Casp8ap2), mediation in activation of the stress-responsive elements upon DNA damage and also regulation of growth and apoptosis (9: Gadd-family, Casp7). A significant portion of the network is occupied by cell cycle pathways (10: Pcna, Cdk1) requiring the G2/M (mitosis) transition (7: Cyclin B1, Cdc20, Ccnb1, Ccnb2, Ccna1), DNA replication and polymerase function (11, 13: Fen1, Pold-family, Bub1b), progression from G1 to S phases (7: Lsm10, Lsm11) as well as the anaphase promoting complex/cyclosome regulation (12: Ube2c, Cdc-family, Mad-family). Presence of the cyclin B1 in the germ plasm of Drosophila was previously described by Dadly and Glover (1992). Other sub-sequential parts of the network are responsible for tissue-specific regulation, including alternative pre-RNA splicing (16: Ddx3y, Cugbp2, Usp9x, Ddx3x), endothelial cell motility and neurotrophic signalling for spinal and sensory neurons (19: Gpi1, Tkt-family), ventral cell fate in the neural tube and normal development of the vertebral column (14: Pax1, Pax9, Msx1, Shh), survival of motor neurons via spliceosomal Sm proteins function (6: Wdr77, Prmt5, Piwifamily, Lsm10, Lsm11) along with methylation of Piwi proteins required for interaction with Tudor-domain contained proteins. 


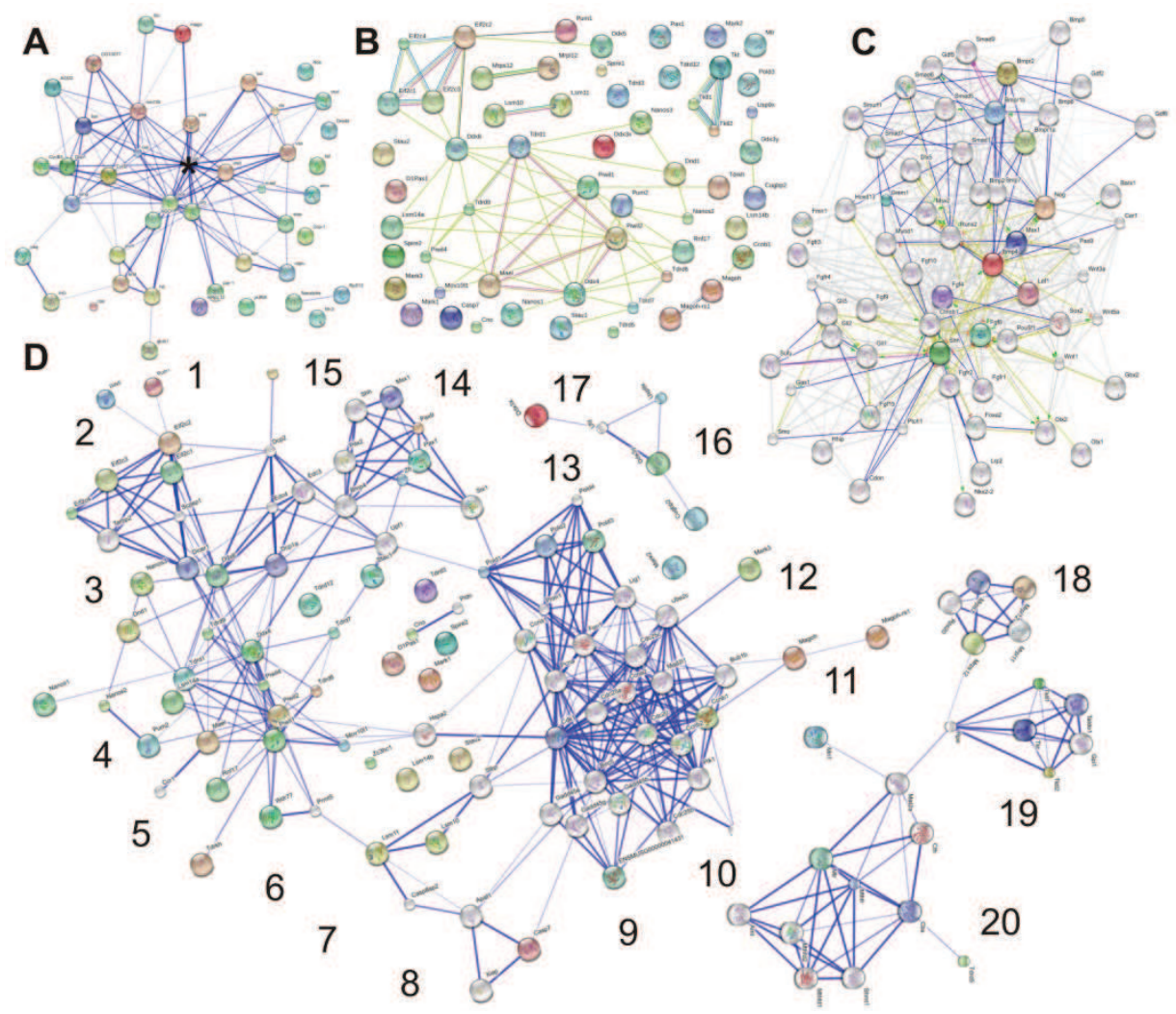

Fig. 6. Protein networks of Drosophila melanogaster germ-plasm (A, confidence mode), homologues (B, evidence mode) and expanded neighbouring interactions ( $\mathrm{D}$, confidence mode; 1-20 functional modules, see in the text) of Mus musculus germ-plasm; and interactions for Mus musculus BMP4 (C, action mode).

It was previously found that BMP-family proteins play an important role in primordial germline specification during normal mammalian development and are also required during germline differentiation of mouse and human ESCs in vitro (see Ying et al, 2001; Toyooka et al, 2003; Kee et al, 2006). The BMP4 protein, along with some nuage/germ granules components, is involved in a complicated network of transcriptional factors regulating early embryo development, stem cell fate and differentiation. Repression of the Shh gene, for example, prevents activation of the transcription for genes involved in ventral cell fate in the neural tube and also disrupts the polarizing signal for patterning of the anterior-posterior axis of the developing limb bud. It is not surprising that network control is looping from one gene to another (Wnt5a, Otx2, Shh, Bmp4, Runx2, Nog, and Fgf8) forming a "switch-off/switch-on" dynamic machinery in the cell cytoplasm (Fig. 6C). It is evident that the germ plasm or nuage complex is the sub-cellular localized organelle controling this "on and off" loop depending on the cell fate. Indeed, the sub-cellular organization and localization of the nuclear pore would serve as a major station processing specific mRNA. Such a station can sort and degrade specific mRNA upon cell fate and 
differentiation via traditional nonsense-mediated mRNA decaying or by non-traditional Stau-based degeneration. Staufen is known to bind double-stranded RNA, along with other members of germ plasm (DEAD-box helicases), but Stau1 also binds tubulin cross-linking RNA macromolecular complexes (MMCs) to the cytoskeleton of the cell. Such organelle organization and function can quickly and reversibly mobilize MMCs to a specific compartment, preceding their post-transcriptional modification, and activate site-specific protein translation and localization. Furthermore, nuage can suppress or even put to silence transposable elements, preventing their mobilization via piRNA-based machinery. This can be done without significant structural changes in genome organization and without transcriptional de-activation of the crucial developmental loci and transcriptional factors that are involved in stem cell pluripotency (Pou5f1 and Sox2).

Besides the function in the germline, the germ plasm components control, or assist in the control, of tissue-specific pathways defining the pattern and fate in stem cell progenitors. They are also responsible for a wide range of gene transcription and translation regulation, as well as the cell cycle. It seems that the germ plasm acts as a switch between mesoderm and ectoderm fate. It stimulates endothelial cell motility, and possibly specifies or regulates the differentiation of cartilage and bone of notochord in chordates. Notochord induces neural plate formation and, by secreting $\mathrm{SHH}$ protein, signals differentiation of motoneurons in the neural tube.

The extensive molecular signatures and functional potential of germ cells and pluripotent stem cells suggest a shared evolutionary origin for these cell types and an ancestral pluripotency network including members of Vasa-like and Piwi-like class proteins, which are conserved components of both germ and stem cells across the metazoans (Alié et al., 2011; Ewen-Campen et al. 2010; Gustafson \& Wessel, 2010; Sroji \& Extavour, 2011). Based on the literature and our own data analysis, we support the idea that this regulatory gene network is not restricted to the germline cells but is expressed in stem cells that are capable of producing both somatic and germinal derivatives.

\section{Conclusion}

The data we have reviewed here suggest the existence of an evolutionary conserved basis of pluripotency and "stemness" of germ and gametogenic pluripotent stem cells. This mechanism is common for all studied metazoan representatives, from sponges to chordates, and operates at cellular, sub-cellular and molecular levels. In the studied asexually reproducing representatives of Porifera, Cnidaria, Platyhelminthes, Arthropoda and Chordata, stem cells serve as the predecessors of germ and somatic cells and are similar to cells of the germ lineage, displaying evolutionarily conserved features of the morphofunctional organization typical also of cells of the germ line (Ewen-Campen et al. 2010; Extavour, 2008; Funayama et al., 2010; Gustafson \& Wessel, 2010; Isaeva et al., 2003, 2008, 2009; Rinkevich et al., 2009; Sköld et al., 2009; Shukalyuk et al., 2005, 2007, 2011; Sroji \& Extavour, 2011). The reaction revealing the activity of alkaline phosphatase, earlier used for the identification of primary germ cells and embryonic stem cells in vertebrates, was successfully applied as a cytochemical marker of invertebrate stem cells (see Agata et al., 2006; Akhmadieva et al., 2007; Isaeva, 2011; Isaeva et al., 2003; Rinkevich et al., 2009; Shukalyuk et al., 2005; Sköld et al., 2009).

Since pluri/multipotent stem cells produce germline cells, they might be considered part of the germline (Mochizuki et al., 2001); such "primary" stem cells may be immortal 
contributing to the germ line, in contrast to somatic tissues (Weismann, 1893; Sköld et al 2009). It is gametogenesis that gives us an "afterlife," propelling our genome into future generations (Seydoux \& Braun, 2006). Pluripotent stem cells of animals with asexual reproduction are predecessors of primary germ cells. Pluripotent gametogenic stem cells and germline cells share many morphological features and rely on the activity of related genes; their evolutionary and ontogenetic relationship has been proposed (Extavour, 2008; Extavour \& Akam, 2003; Sköld et al., 2009; Strouji \& Extavour, 2011).

Adult pluripotent stem cell systems are not restricted to primitive animals and probably evolved as components of asexual reproduction (Agata et al., 2006). The data on the asexual reproduction in some arthropods and chordates contradicts the dogma that asexual reproduction is common exclusively among the lower animals (Isaeva, 2010, 2011).

The term "somatic embryogenesis" (Buss, 1987; Blackstone \& Jasker, 2003) suggests that stem cells, which ensure the asexual reproduction, are recognized as somatic ones; pluripotent stem cells in animals with asexual reproduction are often referred as somatic (Blackstone \& Jasker, 2003; Extavour \& Akam, 2003; Extavour, 2008; Rinkevich, 2009; Sköld et al., 2009; Funayama et al., 2010). However, pluriponent gametogenic stem cells of asexually reproducing invertebrates, like primary germ cells, do not belong to any germ layer, differentiated tissue, and population of specialized somatic cells or their somatic stem cells (Isaeva, 2010, 2011). Such pluripotent stem cells are dispersed in the organism, do not display contact inhibition of cell reproduction and movement and are similar to primary germ cells in their ability to perform amoeboid movements and large-scale migrations within the organism, directed to the localities of asexual reproduction and regeneration or to the gonads, respectively (Isaeva et al., 2008, 2009; Rinkevich et al., 2009; Sköld et al., 2009). We believe that the evolutionarily and ontogenetically related cells of early embryos, pluripotent gametogenic stem cells and germline cells belonging to cell populations capable of realizing the entire developmental program, including gametogenesis (and, potentially, subsequent embryogenesis) are not identical to somatic cells.

Pluripotent cells in invertebrates with asexual reproduction are similar in their potential and their molecular signature to mammalian embryonic stem cells, although the latter are artificial cell systems cultured in vitro. Thus, published and original data indicate the existence of evolutionary conserved, sub-cellular and molecular bases of toti/pluripotency and "immortality" and similarity of studied morphofunctional features and molecular signature of pluripotent stem cells in metazoans with asexual reproduction from sponges and cnidarians to chordates, germline and embryonic stem cells (Fig. 7).

Recent data indicate the broad and partially overlapping spectrum of gene expression in ECSs, germ, and pluri/multipotent potent stem cells, in particular, the possible inducibility of germline cells de novo without continuous expression of molecular markers of the germ line. The data also show a transient molecular signature typical of the germline in broad somatic domains during embryogenesis and the expression of germline marker genes in somatic stem pools. Embryonic stem, germ and pluripotent stem cells of various metazoans share the expression piwi, vasa-related and other germline marker genes. It is possible a functional diversification of paralogues of vasa, piwi and other marker "germline" genes fulfilling different functions in germ and other stem cells. In the animal kingdom, vasa-like genes are present in numbers from one to four (Shibata et al., 1999; Rebscher et al., 2007; Extavour et al., 2005; Pfister et al., 2008). In mammals, four Argonaute subfamily members have been shown to be involved in the miRNA pathway (Parvinen, 2005; Kotaja et al., 2006). 
Although, the canonic, classical germline molecular markers remain reliable for germ cell identification within developing individual across Metazoa, more studies need to be done in order to understand molecular and cellular events underlying pluri/totipotency, stem cell self-renewal and self-preservation during germline specification.

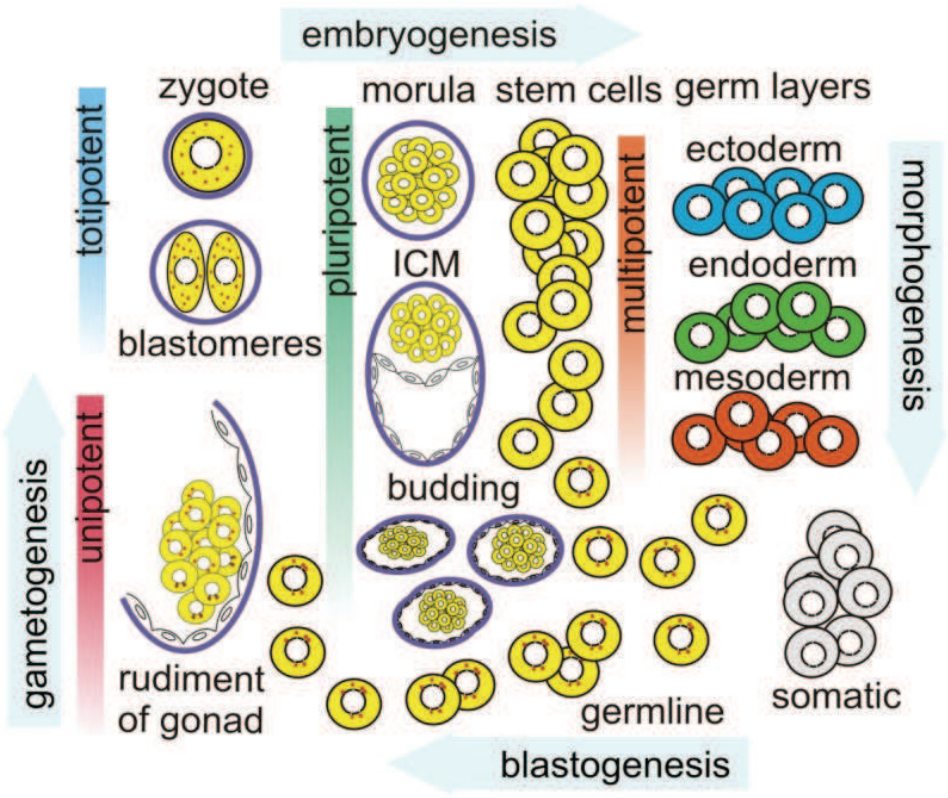

Fig. 7. Germ-plasm material on the sub-cellular level in animals with sexual or both sexual and asexual reproduction in their life span. In animals with epimorphosis, early blastomeres after first few divisions are believed to be fully totipotent along with zygote and capable of producing an entire organism. Macromolecular complexes (MMC, yellow) distributed in cytoplasm and germ-plasm granules around nucleus (in red) are present in zygote and early blastomers marking their totipotent ability. Through the embryonic development, the visual manifestations of the granules are disappeared in the pluripotent cells of morula, inner cell mass of blastocyst or embryonic stem cells in culture. However, specific MMCs are distributed in cytoplasm (yellow) marking their potency. Morphogenesis followed after specification of the three germ layers (ectoderm, endoderm and mesoderm) segregates true somatic cells lacking their potency (grey color) and the germline. The germline lineage expresses the specific MMCs and germ markers de novo during specification. The germplasm activates in granules (red) near nucleus pores. Germline specification occurs from the mesoderm (in mammalians) as well as spontaneously in culture of embryonic stem cells, and from the pool of the stem cells in asexually reproducing organisms. Presumably, reactivation of the germ-plasm in germline forms a unique sub-cellular niche for regulating and manipulating cellular pluripotency. Finally, germline cells with their specific molecular signature migrate and populate the rudiment of the developing gonad. A new signalling niche will significantly restrict germline abilities (to unipotency) during further gametogenesis. Eventually, cells will undergo dramatic morphological and molecular changes (oogenesis and spermatogenesis) ensuring protection and passing of undamaged information to the next generation. 
Germ granules, chromatoid bodies, nuage, P-bodies and so on are the physical embodiment of overlapping but not identical gene networks. The patterns arose ancestrally as a gametogenic/stem program. Germ granules may be as diverse as P-granules of somatic cells, with functions ranging from RNA localization and decay to translational activation and repression (Anderson \& Kedersha, 2006; Seydoux \& Braun, 2006). It is also possible, that in some cases, this machinery exists in mammals as submicroscopic complexes that are rich in RNAs and RNA-binding proteins (Hubbard \& Pera, 2003). The Oskar protein nucleates the formation of polar granules de novo, from cytoplasmic pools of the components shared with nuage. In this model, nuage could be an organelle that concentrates and thus potentiates the activity factors normally present in all cells, but that must be especially active in germline cells because of their intensive reliance on post-transcriptional controls of gene expression (Snee \& Macdonald, 2004). Basic germ-plasm machinery may exist as discrete granules or bodies, large complexes as Balbiani bodies, dispersed nuage, small particles (for example, P-bodies) or submicroscopic RNP aggregates. It seems to us that similar networks in mammalians overlapped with the macromolecular frame of the germinal granules emerging earlier in germline cell evolution. Given that the factors that are associated with germ granules in non-mammalian species are also expressed in mammalian germ cells, we speculate that all multicellular animals share basic germ-plasm machinery, a nuage-like subcellular frame, which operates in a similar manner across Metazoa and might recruit other tissue-specific networks within.

Protection against apoptosis is very important for embryonic, germ and pluripotent stem cells as well as for long living neural precursors and neurons. Differentiation of toti-/ pluripotent cells irrevocably drags their descendants into programmed death. Undifferentiated cells have only two choices: stay undifferentiated and immortal or start to differentiate and die. Breaking this rule leads cells to cancerogenesis. The germline cells and neuronal precursors evolutionarily obtained unique machinery for circumventing this rule, which allows them to continue their differentiation but keep their immortality over the lifespan of the individual. However, cell death does occur during neurogenesis, matching the number of neurons to the number of target cells. It is also known that in zebrafish, loss of piwi-related gene function results in a progressive loss of germ cells due to apoptosis during larval development (Houwing et al., 2007). A mutation of mouse vasa homolog gene $(M v h / D d x 4)$ leads to restricted expression. In homozygotes, premeiotic germ cells cease differentiation and undergo apoptotic death (Tanaka et al., 2000). Studies of apoptosis have revealed the key role of the apoptosis induction factor of mitochondrial origin and apoptogenic functions of cytochrome $\mathrm{C}$ in this important, evolutionary conserved process (Green \& Reed, 1998; Martinou, 1999). Contact with mitochondria is a typical property of germinal granules in diverse multicellular animals. The germinal granules in the cytoplasm of germline cells of Drosophila contain ribosomal RNAs of mitochondrial origin (Amikura et al., 2001). It is not coincidence that several cytochrome $C$ oxidase and other mitochondrial products were found within the germ plasm. Moreover, we propose mitochondrial participation in biogenesis of germ granules (Isaeva et al., 2005; Isaeva, 2011). VASA protein homologue has been found both in germ granules and in the mitochondrial matrices in germ cells of Xenopus embryo (see Watanabe et al., 2009). Similarly, the protein encoded by the tudor-related gene, is present not only in polar granules, but also inside the mitochondria of early embryos of Drosophila (see Ding \& Lipshitz, 1993). We also postulate the presence of molecular defence against apopthosis localized in germinal granules and related 
cytoplasmic structures in germline, embryonic, pluripotent stem and neural cells ensuring self-preservation against cell aging and death.

The hypothesis has been advanced that the germline originally evolved from primary stem cells (Sköld et al., 2009). Extavour (2008) also proposed that germ cells have their evolutionary origins in a pluripotent stem cell population. Taking a different position, Zwaka \& Thomson (2005) hypothesized that embryonic stem and embryonic germ cells represent a family of related pluripotent cell lines, whose common properties reflect a common origin from germ cells. Rebscher et al. (2007) proposed a model in which vasa, piwi, and pl10 ancestrally carried out a first step in germline determination by specifying a multipotent population of stem cells within which PGCs are sorted out later. An ancient association of "germline genes" with stemness (Watanabe et al. 2009) and "an ancestral gene fingerprint of stemness" (Alié et al. 2011) were proposed. The genes vasa and piwi are the most extensively studied of the genes, known as germline markers, which appear to be involved in the ancestral molecular signature of stemness and expressed in pluri-/ multipotent stem cells across animal phyla. According to the hypothesis put forward by Alié et al. (2011), piwi and vasa-related genes belong to a gene network ancestrally associated with stemness. These genes determine gametogenic potential, but the main function of these genes is genome silencing. Agata et al. (2006) proposed that the pluripotent stem cell system supporting both asexual and sexual reproduction in many adult animals represents one type of origin of stem cell systems; the other system developed by separating multiple functions of primitive pluripotent stem cells into specialized cell lineages.

We suppose mainly common and partially overlapping molecular signatures in pluri-/ multipotent stem cells of a wide range of animals from sponges to chordates. But we also suspect a wide spatial and temporal ontogenetic context as a continuum of toti-, pluri-, multipotent state within stem cells. Such a continuum ranges from pluripotent gametogenic stem cells to germline cells and up to multipotent somatic stem cells lacking gametogenic potential. All animals possess pluripotent gametogenic stem cells in different ontogenetic periods: as a transient state in early cleavage until segregation of germ line (preformation), as a longer state during embryogenesis (epigenesis), or as a continuous state during the entire life of asexually reproducing organisms. Pluripotent stem cells have the capacity to move away from pluripotency towards a special, restricted stem cell identity as germ cells (Sroji \& Extavour, 2011) or to restricted identities as somatic multipotent stem cells, oligopotent stem cells and so on. A core regulatory gene network of pluripotent gametogenic stem cells, germline cells and multipotent stem cells evidently overlap to a large extent including also some specific distinctions and fluctuations of key gene expression. Genes of the molecular machinery of stem cells appeared to be interconnected in related pathways that are involved in post-transcriptional regulation and epigenetic modification acting in a coordinated manner, as part of a complex network of signal cascades that are known to regulate the balance between cell death and survival (Rossi et al., 2007). Since all animals have a common ancestor in single cell organisms it is possible to identify common principles in the regulatory mechanisms for the transcriptional and epigenetic machinery but at present there is no clear picture to what extent the regulatory transcriptional network to maintain stem cell function has been conserved during metazoan evolution (Watanabe et al. 2009), in germline cells or beyond the germ line (Gustafson \& Wessel, 2010). 
Taking into consideration our own data and the supporting literature, we see that there is enough evidence to suggest the existence of an ancient molecular basis of toti-, pluri-, or multipotency of germ and stem cells, common for all studied representatives of multicellular animals. However, the detailed molecular mechanisms and overlapping regulatory networks in different stem cell systems appeared to be more complex that was viewed before. Interconnecting regulatory networks of stem cells and germ cells still remain unclear in their capacity to decide cell fate transferring the control from the nuclear transcriptional networks to the cytoplasmic post-transcriptional machinery. Further comparative studies of stem cells in a wide variety of metazoans may provide significant and crucial data for our understanding of the common, evolutionary conservative basis of stemness, pluripotency and potential "immortality" of germ and stem cells across Metazoa.

\section{Acknowledgment}

This study was supported by a grant from the Russian Federation for Basic Research (no. 0904-00019). The authors are grateful to Mr. Brian P. Ettkin for his help and support in manuscript preparation. This review was written in support of the Vladimir L. Kasyanov Foundation promoting developmental biology, stem cell studies and marine life ecology.

\section{References}

Agata, K., Nakajima E., Funayama N., Shibata N., Saito Y. \& Umesono sY. (2006). Two different evolutionary origins of stem cell systems and their molecular basis, Seminars in Cell \& Devel. Biol. Vol. 17: 503-509.

Akhmadieva, A.V., Shukalyuk, A.I., Aleksandrova, Y.N. \& Isaeva, V.V. (2007). Stem cells in asexual reproduction of colonial ascidian Botryllus tuberatus. Russian J. of Marine Biol. Vol. 33 (No.2): 134-137.

Alié, A., Leclère, L., Jager, M., Dauraud, C., Chang, P., Guyader, H., Quéinnec, E., \& Manuel, M. (2011). Somatic stem cells express piwi and vasa genes in an adult ctenophore: ancient association of "germline genes" with stemness. Devel. Biol. Vol. 350: 183197.

Amikura, R., Hanyu, K., Kashikawa, M. \& Kobayashi, S. (2001). Tudor protein is essential for the localization of mitochondrial RNAs in polar granules of Drosophila embryos. Mechanisms of Development Vol. 107, No. 1-2: 97-104.

Anderson, P. \& Kedersha, N. (2006). RNA granules. J. of Cell Biol. Vol. 172: 803-808.

Anne, J. (2010). Targeting and anchoring Tudor in the pole plasm of the Drosophila oocyte. PLoS ONE Vol. 5(No. 12): e14362- e14362.

Arkov, A.L., Wang, J.Y.S., Ramos, A. \& Lehmann, R. (2006). The role of Tudor domains in germline development and polar granule architecture. Development Vol. 133: 40534062.

Atkinson, S. \& Armstrong, L. (2008). Epigenetics in embryonic stem cells: regulation of pluripotency and differentiation. Cell Tissue Research Vol. 331: 23-29.

Berrill, N.J. (1961) Growth, Development, and Pattern, San Francisco, London: Freeman and Company, $556 \mathrm{p}$.

Blackstone, N.W. \& Jasker, B.D. (2003). Phylogenetic consideration of clonality, coloniality, and mode of germline development in animals. J. of Experimental Zoology Vol. 287B: $35-47$. 
Brown, F.D., \& Swalla, B.J. (2007). Vasa expression in a colonial ascidian, Botrylloides violaceus. Evolution \& Development Vol. 9: 165-177.

Buss, L.W. (1987). The Evolution of Individuality, Princeton University Press, Princeton, NJ.

Chambers, I., Colby, D., Robertson, M., Nichols, J., Lee, S., Tweedie, S. \& Smith, A. (2003). Functional expression cloning of Nanog, a pluripotency sustaining factor in embryonic stem cells. Cell Vol. 113: 643-55.

Chuma, S., Hosokawa, M., Kitamura, K., Kasai, S., Fujioka, M., Hiyoshi, M., Takamune, K., Noce, T., \& Nakatsuji N. (2006). Tdrd1/Mtr-1, a tudor-related gene, is essential for male germ-cell differentiation and nuage/germinal granule formation in mice. PNAS USA Vol. 103: 15894-15899.

Cinalli, R.M., Rangan, P. \& Lehmann, R. (2008). Germ Cells Are Forever. Cell Vol. 132: 559562.

Clark, A.T., Bodnar, M.S., Fox, M., Rodriquez, R.T., Abeyta, M.J., Firpo, M.T. \& Pera R.A.R. (2004). Spontaneous Differentiation of Germ Cells from Human Embryonic Stem Cells in vitro, Human Molecular Genetics, Vol. 13, pp. 727-739.

Cox, D.N., Chao, A., Baker, J., Chang, L., Qiao, D. \& Lin, H. (1998). A novel class of evolutionarily conserved genes defined by piwi are essential for stem cell selfrenewal. Genes \& Devel. Vol. 12: 3715-3727.

Coward, S.J. (1974). Chromatoid bodies in somatic cells of the planarian: Observation on their behavior during mitosis. Anatomical Records Vol. 180: 533-546.

De Mulder, K., Kuales, G., Pfister, D., Willems, M., Egger, B., Salvenmoser, W., Thaler, M., Gorny, A. K., Hrouda, M., Borgonie, G. \& Ladurner P. (2009). Characterization of the stem cell system of the acoel Isodiametra pulchra. BMC Dev. Biology Vol. 9: 69

Denker, E., Manuel, M., Leclère, L., Le Guyader, H. \& Rabet, N. (2008). Ordered progression of nematogenesis from stem cells through differentiation stages in the tentacle bulb of Clytia hemisphaerica (Hydrozoa, Cnidaria). Developmental Biology Vol. 315: 99-113.

Dill, K.K. \& Seaver, E.C. (2008). Vasa and nanos are coexpressed in somatic and germ line tissue from early embryonic cleavage stages through adulthood in the Polychaete capitella sp. Genes Devel. \& Evol. Vol. 218: 453-463.

Ding, D. \& Lipshitz, H.D. (1993). A Molecular Screen for Polar-localized Maternal RNAs in the Early Embryo of Drosophila. Zygote Vol. 1: 257-271.

Do, J.T. \& Schöler, H.R. (2009). Regulatory circuits underlying pluripotency and reprogramming. Trends in Pharmacological Sciences Vol. 30: 296-302.

Eddy, E.M. (1975). Germ Plasm and the Differentiation of the Germ Cell Line, Int. Review of Cytology Vol. 43: 229-280.

Eguizabal, C., Shovlin, T.C., Durcova-Hills, G., Surani, A. \& McLaren, A. (2009). Generation of primordial germ cells from pluripotent stem cells. Differentiation Vol. 78: 116-123

Eisenhoffer, G.T., Kang, H. \& Alvarado, A.S. (2008). Molecular analysis of stem cells and their descendants during cell turnover and regeneration in the planarian Schmidtea mediterranea. Cell Stem Cell Vol. 3(No. 3): 327-39.

Eulalio. A., Behm-Ansmant, I. \& Izaurralde, E. (2007). P bodies: at the crossroads of posttranscriptional pathways. Nat Rev Mol Cell Biol Vol. 8: 9-22.

Extavour, C.G.M. (2008). Urbisexuality: the evolution of bilaterian germ cell specification and reproductive systems. In: Evolving Pathways. Key Themes in Evolutionary Developmental Biology, Eds. Minelli, A. \& Fusco, G., Cambridge, New York, 
Melbourne, Madrid, Cape Town, Singapore and Sãn Paulo: Cambridge University Press, pp. 321-342.

Extavour, C.G. \& Akam, M. (2003.) Mechanisms of Germ Cell Specification across the Metazoans: Epigenesis and Preformation. Development Vol. 130: 5869-5884, ISSN 1011-6370

Extavour, C.G., Pang, K., Matus, D.Q. \& Martindale, M.Q. (2005). vasa and nanos expression patterns in a sea anemone and the evolution of bilaterian germ cell specification mechanisms. Evol. \& Devel. Vol. 7: 201-215.

Ewen-Kampen, B., Schwager, E.E. \& Extavour, C.G.M. (2010). The Molecular Machinery of Germ Line Specification. Molecular Reproduction and Development Vol. 77: 3-18.

Flemr, M., Ma, J., Schultz, R.M. \& Svoboda, P. (2010). P-Body loss is concomitant with formation of a messenger RNA storage domain in mouse oocytes. Biology of Reproduction Vol. 82: 1008-1017.

Funayama, N. (2008). Stem cells of sponge, In: Stem Cells. From Hydra to Man, Ed. Bosch T.C.G., Springer, pp. 17-36.

Funayama, N., Nakatsukasa, M., Mohri, K., Masuda, Y., \& Agata, K. (2010). Piwi expression in archeocytes and choanocytes in demosponges: insights into the stem cell system in Demosponges. Evol. E Devel. Vol. 12(No. 3): 275-287.

Green, D.R. \& Reed, J.C. (1998). Mitochondria and Apoptosis. Science Vol. 281 (No. 5381): 1309-1312.

Gustafson, E.A. \& Wessel, G.M. (2010). Vasa genes: emerging roles in the germ line and in multipotent cells. Bioessays Vol. 32: 626-637.

Harrison F.W., De Vos L. Porifera. In: Microscopic Anatomy of Invertebrates. Vol. 2: Placozoa, Porifera, Cnidaria, and Ctenophora. Eds. Harrison F.W., Westfall J.A. Wiley-Liss: New York e a. 1991. P. 28-89.

Hogan, B. (2001). Primordial germ cells as stem cells. In: Stem cell biology, Eds. Marshak, D.R., Gardner, R.L. \& Gottlieb, D., Cold Spring Harbor Laboratory Press, New York, pp. 189-204.

Hori I. 1982. An ultrastructural study of the chromatoid body in planarian regenerative cells. J. of Electron Microscopy Vol. 31: 63-72.

Høeg, J.T. \& Lützen, J. (1993). Comparative morphology and phylogeny of the family Thompsoniidae (Cirripedia, Rhizocephala, Akentrogonida), with descriptions of three new genera and seven new species. Zoologica Scripta Vol. 22: 363-386.

Høeg, J.T. \& Lützen, J. (1995). Life cycle and reproduction in the Cirripedia Rhizocephala. Oceanography and Marine Biology: Annual Review Vol. 33: 427-485.

Høeg, J.T., Glenner, H. \& Shields, J.D. (2005). Cirripedia, Thoracica and Rhizocephala (barnacles). In: Marine Parasites, Eds. Rohde, K. \& Wallingford, U.K., CABI, and Collingwood, Victoria, Australia: CSIRO, pp. 154-165.

Huang, Y., Fang, J., Bedford, M.T., Zhang, Y. \& Xu, R.M. (2006). Recognition of histone H3 lysine- 4 methylation by the double tudor domain of JMJD2A. Science Vol. 5: 748751.

Hubbard, E.J.A. \& Pera, R.R.A. (2003). Germ-cell odyssey: fate, survival, migration, stem cells and differentiation. EMBO reports Vol 4: 352-357.

Ikenishi, K. (1998). Germ plasm in Caenorhabditis elegans, Drosophila and Xenopus. Develop. Growth Differ. Vol. 40: 1-10 
Isaeva, V.V. (2010). The diversity of ontogeny in animals with asexual reproduction, and plasticity of early development. Russian J. of Dev. Biology Vol. 41(No. 5): 285-295.

Isaeva, V.V. (2011). Pluripotent Gametogenic Stem Cells of Asexually Reproducing Invertebrates. In: Embryonic Stem Cells, Vol. 2, InTech (in press).

Isaeva, V.V. \& Akhmadieva, A.V. (2011). Germinal granules in archaeocytes of the sponge Oscarella malakhovi Ereskovsky, 2006. Russian J. of Marine Biol. Vol. 37: 209-216.

Isaeva, V., Akhmadieva, A.V., Alexandrova, Y.N. \& Shukalyuk, A.I. (2009). Morphofunctional organization of reserve stem cells providing for asexual and sexual reproduction of Invertebrates. Russian J. of Dev. Biology Vol. 40(No. 2): 57-68.

Isaeva, V.V., Akhmadieva A., Aleksandrova, Y.N., Shukalyuk, A.I. \& Chernyshev, A.V. (2011). Germinal Granules in Interstitial Cells of the Colonial Hydroids Obelia longissima Pallas, 1766 and Ectopleura crocea Agassiz, 1862. Russian J. of Marine Biol. Vol. 37(No. 4): 303-310.

Isaeva, V.V., Alexandrova, Y. \& Reunov, A. (2005). Interaction between Chromatoid Bodies and Mitochondria in Neoblasts and Gonial Cells of the Asexual and Spontaneously Sexualized Planarian Girardia (Dugesia) tigrina. Invertebrate Reproduction and Development Vol. 48(No. 1-3): 119-128.

Isaeva, V.V., Shukalyuk, A.I. \& Akhmadieva, A.V. (2008). Stem cells in reproductive strategy of asexually reproducing Invertebrates. Russian J. of Marine Biol. Vol. 34(No. 1): 1-8.

Isaeva, V.V., Shukalyuk, A.I. \& Kizilova, E.A. (2003). Revealing of stem cells in colonial interna of the Rhizocephalans Peltogasterella gracilis and Sacculina polygenea at parasitic stage of their life cycle. Tsitologiya Vol. 45(No. 8): 758-763.

Isaeva, V.V., Shukalyuk, A.I., Korn, O.M. \& Rybakov, A.V. (2004). Development of primordial externae in the colonial interna of Polyascus polygenea (Crustacea: Cirripedia: Rhizocephala). Crustacean Research No. 33: 61-71.

Isaeva, V.V., Shukalyuk, A.I., Trofimova, A.V., Korn, O.M. \& Rybakov, A.V. (2001). The structure of colonial interna in Sacculina polygenea (Crtustacea: Cirripedia: Rhizocephala). Crustacean Research No. 30: 134-147.

Ivanova-Kazas, O.M. (1996). Blastogenesis, Cormogenesis, and Evolution. Russian J. of Marine Biol. Vol. 22(No. 5): 285-294.

Jaenisch, R. \& Young, R. (2008). Stem cells, the molecular circuitry of pluripotency and nuclear reprogramming. Cell Vol. 132: 567-582.

Juliano, C.E., Yajima, M. \& Wessel, G.M. (2010). Nanos functions to maintain the fate of the small micromere lineage in the sea urchin embryo. Dev. Biol. Vol. 337: 220-232.

Juliano, C. \& Wessel, G. (2010). Versatile germline genes. Science Vol. 329: 640-641.

Kee, K., Gonsalves, J.M., Clark, A.M. \& Pera R.R.A. (2006). Bone morphogenetic proteins induce germ cell differentiation from human embryonic stem cells. Stem cells and Development Vol. 15: 831-837.

Kiebler, M.A. \& Bassell, G.J. (2006). Neuronal RNA Granules: Movers and Makers. Neuron Vol. 51: 685.

Kim, J., Chu, J., Shen, X., Wang, J. \& Orkin, S.H. (2008). An extended transcriptional network for pluripotency of embryonic stem cells. Cell Vol. 132: 1049-1061.

Kloc, M., Bilinski, S. \& Etkin, L.D. (2004). The Balbiani body and germ cell determinants: 150 Years Later. Current Topics in Dev. Biol. Vol. 59: 1-36.

Kotaja, N., Bhattacharyya, S.N., Jaskiewicz, L., Kimmins, S., Parvinen, M., Filipowicz, W. \& Sassone-Corsi, P. (2006). The chromatoid body of male germ cells: Similarity with 
processing bodies and presence of Dicer and microRNA pathway components. PNAS Vol. 103: 2647-2652.

Lacham-Kaplan, O., Chy, H., Trounson, A. (2006). Testicular cell conditioned medium supports differentiation of embryonic stem cells into ovarian structures containing oocytes. Stem Cells Vol. 24: 266-273.

Lachke, S.A., Alkuraya, F.S., Kneeland, S.C., Ohn, T., Aboukhalil, A., Howell, G.R., Saadi, I., Cavallesco, R., Yue, Y., Tsai, A.C.-H., Nair, K.S., Cosma, M.I., Smith, R.S., Hodges, E., AlFadhli, S.M., Al-Hajeri, A., Shamseldin, H.E., Behbehani, A.M., Hannon, G.J., Bulyk, M.L., Drack, A.V., Anderson, P.J., John, S.W.M. \& Maas, R.L. (2011). Mutations in the RNA granule component TDRD7 cause cataract and glaucoma. Science Vol. 331: 1571-1576.

Leatherman, J.L., \& Jongens, T.A. (2003). Transcriptional silencing and translational control: key features of early germline development. Bioessays Vol. 25: 326-335.

Lim, A.K. \& Kai, T. (2007). Unique germ-line organelle, nuage, functions to repress selfish genetic elements in Drosophila melanogaster. PNAS USA Vol. 104: 6714-6719.

Mahowald, A.P. (2001). Assembly of the Drosophila germ plasm. Int. Review of Cytology Vol. 203: 187-213.

Martinou, J.C. (1999). Key to the mitochondrial gate. Nature Vol. 399(No. 6735): 411-412.

Matova, N. \& Cooley, L. (2001). Comparative aspects of animal oogenesis. Dev. Biol. Vol. 16: $1-30$.

Mochizuki, K., Sano, H., Kobayashi, S., Nishimiya-Fujisawa, C. \& Fujisawa, T. (2000). Expression and evolutionary conservation of nanos-related genes in Hydra. Development, Genes and Evolution Vol. 210: 591-602.

Mochizuki, K., Nishimiya-Fujisawa, C. \& Fujisawa, T. (2001). Universal occurrence of the vasa-related genes among Metazoans and their germline expression in Hydra. Development, Genes and Evolution Vol. 211: 299-308.

Muraro, N.I., Weston, A.J., Gerber, A.P., Luschnig, S., Moffat, K.G. \& Baines, R.A. (2008). Pumilio binds para mRNA and requires Nanos and Brat to regulate sodium current in Drosophila motoneurons. J. Neurosci. Vol. 28: 2099-2109.

Nagamori, I., Cruickhank, A. \& Sassone-Corsi, P. (2011). The chromatoid body: a specialized RNA granule of male germ cells. Epigenetics and Human Health Vol. 4: 311-328.

Noda, K. \& Kanai, C. (1977). An ultrastructural observation of Pelmatohydra robusta at sexual and asexual stages, with a special reference to "germinal plasm". J. Ultrastructural Research Vol. 61: 284-294.

Oyama, A. \& Shimizu, T. (2007). Transient occurrence of vasa-expressing cells in nongenital segments during embryonic development in the oligochaete annelid Tubifex tubifex. Development, Genes and Evolution Vol. 217: 675-690.

Parvinen, M. (2005). The chromatoid body in spermatogenesis. Int. J. Androl. Vol. 28: 189201.

Pepling, M.E., Wilhelm, J.E., O'Hara, A.L., Gephardt, G.W. \& Spradling, A.C. (2007). Mouse oocytes within germ cell cysts and primordial follicles contain a Balbiani body. PNAS Vol. 104: 187-192.

Pepling, M.E. (2010). A novel maternal mRNA storage compartment in mouse oocytes. Biology of Reproduction Vol. 82(No. 5): 807-808.

Peters, L. \& Meister, G. (2007). Argonaute proteins: mediators of RNA silencing. Mol. Cell Vol. 26: 611-623. 
Pfister, D., De Mulder, K., Hartenstein, V., Kuales, G., Borgonie, G., Marx, F., Morris, J. \& Ladurner, P. (2008). Flatworm stem cells and the germ line: developmental and evolutionary implications of macvasa expression in Macrostomum lignano. Dev. Biol. Vol. 319: 146-159.

Rangan, P., DeGennaro, M., Jaime-Bustamante, K., Coux, R.X., Martinho, R.G. \& Lehmann, R. (2009). Temporal and Spatial Control of Germ-Plasm RNAs. Current Biology Vol. 19: 72-77.

Reddien, P.W., Oviedo, N.J., Jennings, J.R., Jenkin, J.C. \& Alvarado, S.A. (2005). SMEDWI-2 is a PIWI-like protein that regulates planarian stem cells. Science Vol. 310: 13271330.

Rebscher, N., Zelada-González, F., Banish, T., Raible, F. \& Arendt, D. (2007). Vasa Unveils a Common Origin of Germ Cells and of Somatic Stem Cells from the Posterior Embryonic Stem Cells Growth Zone in the Polychaete Platynereis dumerlii. Dev. Biol. Vol. 306: 599-611.

Rebscher, N., Volk, C., Teo, R., \& Plickert, G. (2008). The Germ Plasm Component vasa Allows Tracing of the Interstitial Stem Cells in the Cnidarian Hydractinia echinata. Dev. Dyn. Vol. 237: 1736-1745.

Rinkevich, B. (2009). Stem Cells: Autonomy Interactors that Emerge as Causal Agents and Legitimate Units of Selection, In: Stem Cells in Marine Organisms, Eds. Rinkevich, B. \& Matranga, V., Springer: Dordrecht, Heidelberg, London, New York, pp. 1-20.

Rinkevich, Y., Matranga, V., Rinkevich, B. (2009). Stem cells in aquatic invertebrates: common premises and emerging unique themes. In: Stem Cells in Marine Organisms, Eds. Rinkevich, B., Matranga, V., Springer: Dordrecht, Heidelberg, London, New York, pp. 61-104.

Rosner, A., Moiseeva, E., Rinkevich, Y., Lapidot, Z. \& Rinkevich, B. (2009). Vasa and the germ line lineage in a colonial urochordate. Developmental Biology Vol. 331: 113-128.

Rossi, L., Salvetti, A., Marincola, F.M., Lena, A., Deri, P., Mannini, L., Batistoni, R., Wang, E. \& Gremigni, V. (2007). Deciphering the molecular machinery of stem cells: a look at the neoblast gene expression profile. Genome Biology Vol.8: R62.

Salvetti, A., Rossi, L., Lena, A., Batistoni, R., Deri, P., Rainaldi, G., Locci, M.T., Evangelista, M. \& Gremigni, V. (2005). DjPum, a homologue of Drosophila Pumilio, is essential to planarian stem cell maintenance. Development Vol. 132: 1863-1874.

Seipel, K., Yanze, N., \& Schmid, V. (2004). The germ line and somatic stem cell gene Cniwi in the jellyfish Podocoryne carnea. Int. J. Dev. Biol. Vol. 48: 1-7.

Selenko, P., Sprangers, R., Stier, G., Bühler, D., Fischer, U. \& Sattler, M. (2001). SMN Tudor domain structure and its interaction with the Sm proteins. Nature Structural Biology Vol. 8(No. 1): 27-31.

Seydoux, G. \& Braun, R.E. (2006). Pathway to totipotency: lessons from germ cells. Cell Vol. 127: 891-904.

Shibata, N., Rauhana, L. \& Agata, K. (2010). Cellular and molecular dissection of pluripotent adult somatic stem cells in planarians. Development, Growth and Diff. Vol. 52: 27-41.

Shibata, N., Umesono, Y., Orii, H., Sakurai, T., Watanabe, K. \& Agata, K. (1999). Expression of vasa (vas)-related genes in germline cells and totipotent somatic stem cells of planarians. Develop. Biol. V. 206: 73-87.

Shostak, S. (2006). (Re)defining stem cells. BioEssays Vol. 28: 301-308. 
Shukalyuk, A.I., (2002). Organization of interna in Sacculina polygenea (Crustacea: Rhizocephala). Russian Journal of Marine Biology Vol. 28: 329-335.

Shukalyuk, A.I. (2009). Germline commitment in embryonic and induced pluripotent stem cells. Proceeding of The American Society of Cell Biology: 49th Annual Meeting, December 5-9, Regular Abstracts, pp. 585.

Shukalyuk, A.I., Baiborodin, S.I. \& Isaeva, V.V. (2001). Organization of interna in the rhizocephalan barnacle Peltogasterella gracilis. Russian J. of Marine Biol. Vol. 27: 113116.

Shukalyuk, A.I., Golovnina, K., Baiborodin, S., Gunbin, K., Blinov, A. \& Isaeva, V. (2007). vasa-related genes and their expression in stem cells of colonial parasitic rhizocephalan barnacle Polyascus polygenea (Arthropoda: Crustacea: Cirripedia: Rhizocephala). Cell Biology International Vol. 31(No. 2): 97-108.

Shukalyuk, A.I., Isaeva, V.V., Akhmadieva, A.V., \& Alexandrova, Y.N. (2011). Stem cells in asexually reproducing invertebrates, embryonic stem cells and germline cells share common, evolutionary conserved features. Proceeding of the International Society for Stem Cell Research, 9th Annual Meeting, June 15-18, Friday Abstracts, Toronto, p. 77.

Shukalyuk, A.I., Isaeva, V.V., Golovnina, K.A., Baiborodin, S.I. \& Blinov, A.G. (2005). vasarelated genes and their expression in stem cells of colonial Polyascus polygenea (Crustacea: Cirripedia: Rhizocephala). Proceeding of the International Society for Stem Cell Research: 3rd Annual Meeting, San Francisco. Abstracts. p. 215.

Shukalyuk, A.I., Isaeva, V.V., Kizilova, E. \& Baiborodin, S. (2005). Stem cells in reproductive strategy of colonial rhizocephalan crustaceans (Crustacea: Cirripedia: Rhizocephala). Invertebrate Reproduction and Development Vol. 48: 41-53.

Shukalyuk, A.I. \& Stanford, W.L. (2008). Germ plasm signature in embryonic stem cells. Proceeding of the International Society for Stem Cell Research, $6^{\text {th }}$ Annual Meeting, June 11-14, Philadelphia, USA, p. 353 N 238.

Sköld, H.N., Obst, M., Sköld, M. \& Åkesson, B. (2009). Stem cells in asexual reproduction of marine invertebrates. In: Stem Cells in Marine Organisms. Eds. Rinkevich, B. \& Matranga, V., Springer: Dordrecht, Heidelberg, London, New York, pp.105-137.

Snee, M.J. \& Macdonald, P.M. (2004). Live imaging of nuage and polar granules: evidence against a precursor-product relationship and a novel role for Oskar in stabilization of polar granule components. Journal of Cell Science Vol. 117: 2109-2120.

Snel, B., Lehmann, G., Bork, P. \& Huynen, M.A. (2000). STRING: a web-server to retrieve and display the repeatedly occurring neighbourhood of a gene. Nucleic Acids Res. Vol. 28(No. 18): 3442-3444.

Solana, J., Lasko, P. \& Romero, R. (2009). Spoltud-1 is a chromatoid body component required for planarian long-term stem cell self-renewal. Dev. Biol. Vol. 328(No. 2): 410-421.

Srouji, J. \& Extavour, C. (2011). Redefining stem cells and assembling germ plasm: key transition in the evolution of the germ plasm. In: Key transition in animal evolution, Eds. DeSalle, R. \& Schierwater, B., Science Publishers New York, USA Abingdon, UK, pp. 360-397.

Stice, S.L., Boyd, N.L., Dhara, S.K., Gerwe, B.A., Machacek, D.W. \& Shin, S. (2006). Human embryonic stem cells: challenges and opportunities. Reproduction, Fertility $\mathcal{E}$ Development Vol. 18: 839-846. 
Sunanaga, T., Watanabe, A. \& Kawamura, K. (2007). Involvement of vasa homolog in germline recruitment from coelomic stem cells in budding tunicates. Dev. Genes Evol. Vol. 217: 1-11.

Takamura, K., Fujimura, M. \& Yamaguchi, Y. (2002). Primordial germ cells originate from the endodermal strand cells in the ascidian Ciona intestinalis. Dev. Genes Evol. Vol. 212: 11-18.

Tanaka, S.S., Toyooka, Y., Akasu, R., Katoh-Fukui, Y., Nakahara, Y., Suzuki, R., Yokoyama, M. \& Noce, T. (2000). The mouse homolog of Drosophila Vasa is required for the development of male germ cells Genes $\mathcal{E}$ Dev. Vol. 14: 841-853.

Thomson, T. \& Lin, H. (2009). The biogenesis and function of PIWI proteins and piRNAs: progress and prospect. Annual Review of Cell \& Dev. Biology Vol. 25: 355-376.

Toyooka, Y., Tsunekawa, N., Akasu, R., \& Noce, N. (2003). Embryonic stem cells can form germ gells in vitro. PNAS USA Vol. 100: 11457-11462.

Tropere, V., Hitoshi, S., Sigard, C., Mak, T.W., Rossant, J., \& van der Kooy, D. (2001). Direct neural fate specification from embryonic stem cells: a primitive mammalian neural stem cell stage acquired through a default mechanism. Neuron Vol. 30: 65-78.

Updike, D.L., Hachey, S.J., Kreher, J. \& Strome, S. (2011). P granules extend the nuclear pore complex environment in the C. elegans germ line. J. Cell Biol. Vol. 192: 939-948.

Voronina, E., Lopez, M., Juliano, C.E., Gustafson, E., Song, J.L., Extavour, C., George, S., Oliveri, P., McClay, D. \& Wessel, G. (2008). Vasa protein expression is restricted to the small micromeres of the sea urchin, but is inducible in other lineages early in development. Dev. Biol. Vol. 314: 276-286.

Walker, E., Ohishi, M., Davey, R.E., Zhang, W., Cassar, P.A., Tanaka, T.S., Der, S.D., Morris, Q., Hughes, T.R., Zandstra, P.W. \& Stanford W.L. (2007). Prediction and testing of novel transcriptional networks regulating embryonic stem cell self-renewal and commitment. Cell Stem Cell Vol. 1: 71-86.

Watanabe, H., Hoang, V.T., Mättner, R. \& Holstein, T.W. (2009). Immortality and the base of multicellular life: Lessons from chidarian stem cells. Semin. Cell Devel. Biol. Vol. 20: 1114-1125.

Weismann, A. (1892). Das Keimplasma. Eine Theorie der Vererbung, Jena: Verlag von Gustav Fisher, $682 \mathrm{~S}$.

Weismann. A. (1893). The Germ Plasm. A Theory of Heredity, New York: Charles Scriber's Sons, $468 \mathrm{p}$.

Wu, H.-R., Chen, Y.-T., Su, Y.-H., Luo, Y.J., Holland, L.Z. \& Yu, K. (2011). Asymmetric localization of germline markers Vasa and Nanos during early development in the amphioxus Branchiostoma floridae. Develop. Biol. Vol. 353: 147-159.

Ying, Y., Qi, X. \& Zhao, G.Q. (2001). Induction of primordial germ cells from murine epiblasts by synergistic action of BMP4 and BMP8B signaling pathways. PNAS USA Vol. 98: 7858-7862.

Zwaka, T.P. \& Thomson, J.A. (2005). A germ cell origin of embryonic stem cells? Development Vol. 132: 227-233. 


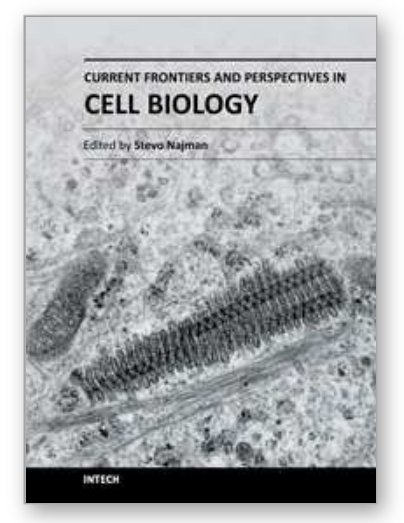

\section{Current Frontiers and Perspectives in Cell Biology \\ Edited by Prof. Stevo Najman}

ISBN 978-953-51-0544-2

Hard cover, 556 pages

Publisher InTech

Published online 25, April, 2012

Published in print edition April, 2012

\section{How to reference}

In order to correctly reference this scholarly work, feel free to copy and paste the following:

Andrey I. Shukalyuk and Valeria V. Isaeva (2012). Molecular and Sub-Cellular Gametogenic Machinery of Stem and Germline Cells Across Metazoa, Current Frontiers and Perspectives in Cell Biology, Prof. Stevo Najman (Ed.), ISBN: 978-953-51-0544-2, InTech, Available from: http://www.intechopen.com/books/currentfrontiers-and-perspectives-in-cell-biology/molecular-and-sub-cellular-gametogenic-machinery-of-stem-andgermline-cells-across-metazoa

\section{INTECH}

open science | open minds

\section{InTech Europe}

University Campus STeP Ri

Slavka Krautzeka 83/A

51000 Rijeka, Croatia

Phone: +385 (51) 770447

Fax: +385 (51) 686166

www.intechopen.com

\section{InTech China}

Unit 405, Office Block, Hotel Equatorial Shanghai

No.65, Yan An Road (West), Shanghai, 200040, China

中国上海市延安西路65号上海国际贵都大饭店办公楼405单元

Phone: +86-21-62489820

Fax: +86-21-62489821 
(C) 2012 The Author(s). Licensee IntechOpen. This is an open access article distributed under the terms of the Creative Commons Attribution 3.0 License, which permits unrestricted use, distribution, and reproduction in any medium, provided the original work is properly cited. 